\title{
Analysis of Astragalus Polysaccharide Intervention in Heat-Stressed Dairy Cows' Serum Metabolomics
}

\author{
Hanfang Zeng ${ }^{1}{ }^{\circledR}$, Yumeng $\mathrm{Xi}^{2}$, Yeqing $\mathrm{Li}^{1}$, Zedong Wang ${ }^{1}$, Lin Zhang ${ }^{1}$ and Zhaoyu Han ${ }^{1, *}$ \\ 1 Institute of Dairy Science, College of Animal Science and Technology, Nanjing Agricultural University, \\ Nanjing 210095, China; zenghanfang9303@163.com (H.Z.); 2016105006@njau.edu.cn (Y.L.); \\ wangzedong@caas.cn (Z.W.); zhanglin9107@163.com (L.Z.) \\ 2 Animal Husbandry Institute, Jiangsu Academy of Agricultural Sciences, Nanjing 210014, China; \\ xiyumengxielei@163.com \\ * Correspondence: zyhan6708@njau.edu.cn; Tel.: +13851685522; Fax: +02584395314
}

Received: 24 February 2020; Accepted: 27 March 2020; Published: 29 March 2020

Simple Summary: Heat stress reduces cow growth, milk yield and reproductive performance, and results in a significant economic loss for the dairy industry. Astragalus polysaccharides (APS), one major active ingredient of astragalus, have a wide range of biological activities. The results of the study revealed that APS has a significant effect on the levels of cortisol (COR), triiodothyronine (T3) and thyroxine (T4) in dairy cows' serum under heat stress. Moreover, twenty metabolites were identified as potential biomarkers for the diagnosis of APS in heat-stressed dairy cows, and APS regulates the energy metabolism of heat stressed dairy cows through glucose metabolism and amino acid metabolism.

Abstract: This experiment was conducted to investigate the effects of astragalus polysaccharides (APS) on serum metabolism of dairy cows under heat stress. Thirty healthy Holstein dairy cows were randomly divided into three groups (10 cows in each group). In the experimental group, $30 \mathrm{~mL} / \mathrm{d}$ (Treatment I) and $50 \mathrm{~mL} / \mathrm{d}$ (Treatment II) of APS injection were injected into the neck muscle respectively. Each stage was injected with APS for 4 days (8:00 a.m. every day) and stopped for 3 days. Serum hormone and antioxidant indexes of dairy cows were investigated. Through repeated measurement analysis of variance, the results have shown that cortisol (COR) $(\mathrm{F}=6.982$, $p=0.026)$, triiodothyronine $(\mathrm{T} 3)(\mathrm{F}=10.005, p=0.012)$ and thyroxine $(\mathrm{T} 4)(\mathrm{F}=22.530, p=0.002)$ at different time points were significantly different. COR showed a downward trend, $\mathrm{T} 3$ and $\mathrm{T} 4$ showed an upward trend. At each time point, different concentrations of APS have significant effects on COR $(\mathrm{F}=30.298, p=0.000<0.05), \mathrm{T} 3(\mathrm{~F}=18.122, p=0.001)$, and T4 $(\mathrm{F}=44.067, p=0.000<0.05)$. However, there were no significant differences in serum insulin (INS), glucagon (GC) and heat shock protein 70 (HSP70) between different time points $(p>0.05)$ and at each time point $(p>0.05)$. Additionally, the results have also shown that there were also no significant differences in serum Superoxide dismutase (SOD), malondialdehyde (MDA) and lactate dehydrogenase (LDH) between different time points $(p>0.05)$ and at each time point $(p>0.05)$. However, the injection of APS had a significant impact on glutathione peroxidase (GSH-Px) $(\mathrm{F}=9.421, p=0.014)$ at different times, and showed a trend of rising first and then falling. At each time point, APS of different concentrations had no significant effect on GSH-Px ( $p>0.05)$. Furthermore, we used gas chromatography-mass spectrometry (GC-MS) non-targeted metabolomics to determine the potential markers of APS for heat-stressed dairy cows. Twenty metabolites were identified as potential biomarkers for the diagnosis of APS in heat-stressed dairy cows. These substances are involved in protein digestion and absorption, glutathione metabolism, prolactin signaling pathway, aminoacyl-tRNA biosynthesis, pentose and glucuronate interconversions, and so on. Our findings suggest that APS have an effect on the serum hormones of heat-stressed dairy cows, and regulate the metabolism of heat-stressed dairy cows through glucose metabolism and amino acid metabolism pathways. 
Keywords: astragalus polysaccharides; heat stress; serum metabolomics; dairy cows

\section{Introduction}

Warming of the global climate environment limits the development of China's dairy industry, especially in the high temperature and high humidity environment found in southern China. These environmental conditions cause cows to be under heat stress for a long time during the summer, ultimately leading to decreases in feed intake, reduced milk quality and reproduction $[1,2]$. Moreover, the incidence of mastitis in cows during the summer has increased, posing a serious challenge to dairy companies [3].

Most Chinese herbal medicines are extracted from pure natural green plants and contain a variety of bioactive substances. Previous studies have indicated that Chinese herbal medicine has a positive impact on the growth performance, immune response and serum metabolic index of livestock and poultry [4-6]. The study also showed that adding a particular fermented Chinese herbal medicine to the diet of dairy cows under high temperature stress could not only significantly improve milk yield, milk fat and milk protein, but also improve the immune function of dairy cows [7]. Furthermore, Chinese herbal medicine has few toxic side effects on animals, and is therefore a potential substitute for antibiotics in feed additives [8].

Astragalus is a major medicinal herb commonly used in many herbal formulations in the practice of traditional Chinese medicine [9]. A previous study indicated that dietary supplementation with $0.5 \%$ fermented Astragalus has beneficial effects on the growth performance, serum biochemical parameters, and fecal microbiota of broiler chickens [10]. A previous study also indicated that herbal medicine Huangqi decoction protected mice against chronic cholestatic liver injury and biliary fibrosis [11]. The major components of astragalus that have been identified are polysaccharides, flavonoids, saponins, and amino acids, and various biological activities of the compounds have been reported [9]. In recent years, scholars have paid attention to the biological value of astragalus polysaccharides (APS) [12,13]. Studies have shown that APS have good antioxidant activity both in vitro and in vivo. This is mainly achieved by improving the activity of superoxide dismutase (SOD) and glutathione peroxidase (GSH-Px) while reducing the production of malondialdehyde (MDA) $[14,15]$. Research shows that APS at higher doses $\left(25 \mathrm{mg} \cdot \mathrm{mL}^{-1}\right)$ have stronger anti-tumor effects, decreasing more than $40.5 \%(24 \mathrm{~h})$ and $67.3 \%$ (48 h) of liver cancer HepG2 cell viability. Thus, in vitro assays suggest that APS possess strong anti-tumor properties, which are beneficial for the treatment of liver cancer [16]. Moreover, evidence from previous research shows that APS inhibit cell growth and pro-inflammatory responses in IL-1beta-stimulated fibroblast-like synoviocytes [17]. APS also have a beneficial role in diabetes [18]. However, little is known about the potential mechanisms in dairy cows under heat stress.

Metabolic profiling, known as metabolomics, is increasingly used in clinical pharmacology and is an ideal tool for the acquisition of the several thousand metabolite alterations that are applied in the relationship between endogenous metabolite metabolism and body metabolism [19]. Metabonomics has been applied in cow science and has predicted the risk of diseases [20] and has been used for biomarker and pathway discovery in some metabolic diseases in cows [21]. A study has shown that 41 biomarkers in plasma metabolites of heat-stressed dairy cows have been identified. All these potential biomarkers are related to the metabolism of amino acids, lipids, carbohydrates, or intestinal microorganisms, which helps to clarify the physiological mechanism of heat stress-induced metabolic disorders and evaluate these biomarkers in practical applications [22]. Additionally, as potential biomarkers, glucose, lactate, pyruvate, lactose, $\beta$-hydroxybutyrate, citric acid, $\alpha$-ketoglutarate, urea, creatine, and orotic acid, had high sensitivity and specificity for heat stress diagnoses. These substances are involved in glycolysis, and in lactose, ketone, tricarboxylic acid, amino acid and nucleotide metabolism, indicating that heat stress mainly affects lactose, energy and nucleotide metabolism of lactating dairy cows [23]. Therefore, metabonomics can provide a better understanding of the 
key metabolites, metabolic pathways, and major regulatory processes in heat-stressed dairy cows. However, how APS influences heat-stressed dairy cows remains undetermined. Therefore, identifying APS in heat-stressed cow serum metabolites and understanding their key pathways can deepen our understanding of APS in dairy cows.

Consequently, in order to analyze the effects of APS on heat-stressed dairy cows, we measured the serum hormones and antioxidant indexes in dairy cows. We also used non-targeted serum metabolomics to investigate the effects of APS on serum metabolism, and analyzed potential biomarkers of energy metabolism in heat-stressed dairy cows. These results might facilitate our understanding of the potential roles of APS in the intermediary metabolism of dairy cows under heat stress.

\section{Material and Methods}

\subsection{Animals Ethics Statement}

The procedures used in the present study were in compliance with the laws and regulations of China (based on the Animal Welfare Committee of Nanjing Agricultural University, China), and the internationally accepted principles and guidelines for the care and use of agricultural, laboratory, or experimental animals.

\subsection{Animals and Experiment Design}

Thirty healthy Holstein dairy cows were randomly divided into three groups (10 cows in each group). Information about parity, lactation days and milk yield of the cows is shown in Table 1 . According to the amount of APS used in previous studies [24,25], in which APS is based on the content of glucose $\left(\mathrm{C}_{6} \mathrm{H}_{12} \mathrm{O}_{6}\right)$ as the dose standard, $10 \mathrm{~mL}$ APS injections containing $0.1 \mathrm{~g}$ APS (Hebei Yuanzheng Pharmaceutical CO., LtD, Shijiazhuang, China), $30 \mathrm{~mL} / \mathrm{d}$ (Treatment I) and $50 \mathrm{~mL} / \mathrm{d}$ (Treatment II) of APS injection were injected into cows in this experiment, respectively. In order to facilitate the absorption of APS and reduce the stress response of dairy cows [26], we used neck muscular injection. Each stage was injected with APS for 4 days (8:00 a.m. every day) and stopped for 3 days. The experiment lasted for 21 days. In the whole experiment, we operated slowly, disinfected and stanched bleeding in time, and the cows did not show discomfort. The cows in the trial were fed three times daily, at $\sim 0700,1330$ and $1900 \mathrm{~h}$. The ingredients and composition of the experimental diets are presented in Table 2. Additionally, cows were allowed free access to water at all the time. Moreover, the cows were milked three times daily, at 0800,1430 and $2000 \mathrm{~h}$. In addition, Treatment I was selected as a metabolomics study subject. Blood samples were collected from tail vein before (day 0,Q), during (day 4, Z) and after (day 21, H) to separate serum. Gas chromatography-mass spectrometry (GC-MS) was used to detect the changes of serum metabolites in dairy cows exposed to stress by non-targeted metabolomics (Shanghai Luming Biotechnology Co., Ltd., Shanghai, China).

Table 1. Characteristics of the Holstein dairy cows used in the study.

\begin{tabular}{ccccc}
\hline Parameter & CON & Treatment I & Treatment II & $p$-value \\
\hline Number of cows & 10 & 10 & 10 & \\
Parity & $1.88 \pm 0.83$ & $2.00 \pm 0.75$ & $1.75 \pm 0.89$ & 0.83 \\
Lactation days(d) & $211.25 \pm 43.21$ & $217.00 \pm 44.28$ & $195.25 \pm 59.10$ & 0.42 \\
Mike yield (kg/d) & $34.62 \pm 4.78$ & $34.62 \pm 5.62$ & $34.62 \pm 4.07$ & 1.00 \\
\hline
\end{tabular}

Note: CON, control group; Treatment I, $30 \mathrm{~mL} / \mathrm{d}$ APS injection; Treatment II, $50 \mathrm{~mL} / \mathrm{d}$ APS injection. 
Table 2. Composition and nutrient levels of basal diet of dairy cows (DM basis) \%.

\begin{tabular}{cccc}
\hline Item & Content(\%) & Item & Content \\
\hline Silage corn & 17.47 & Nutrient levels $(2)$ & \\
Alfalfa grass & 20.66 & $\mathrm{DM}(\%)$ & 57.10 \\
Corn flour & 21.01 & $\mathrm{ME}(\mathrm{MJ} / \mathrm{kg})$ & 11.16 \\
Cardamom & 8.00 & $\mathrm{NE}_{\mathrm{L}}(\mathrm{MJ} / \mathrm{kg})$ & 7.20 \\
Oatgrass & 5.02 & $\mathrm{CP}(\% \mathrm{DM})$ & 17.40 \\
Wet brewer's grains & 4.53 & $\mathrm{NDF}(\%)$ & 30.85 \\
Beet pulp & 5.13 & $\mathrm{ADF}(\%)$ & 19.59 \\
Cottonseed & 4.68 & $\mathrm{EE} \mathrm{( \% )}$ & 5.56 \\
Rapeseed meal & 1.20 & $\mathrm{Ash}(\%)$ & 7.73 \\
Puffed soybean & 3.95 & $\mathrm{Ca}(\%)$ & 0.65 \\
Tablet corn & 2.40 & $\mathrm{P}(\%)$ & \\
DDGS & 2.43 & & \\
Premix $(1)$ & 1.05 & & \\
Fatty acid calcium & 0.43 & & \\
Calcium hydrogen phosphate & 0.50 & & \\
Baking soda & 0.74 & & \\
Salt & 0.50 & & \\
MgO & 0.30 & & \\
Total & 100.00 & & \\
\hline
\end{tabular}

(1) The premix provided the following per kg of diets: VA $5130 \mathrm{IU}, \mathrm{VD}_{3} 1283 \mathrm{IU}$, VE $26 \mathrm{mg}$, biotin $0.05 \mathrm{mg}$, $\beta$-carotene $0.10 \mathrm{mg}, \mathrm{Mn} 12 \mathrm{mg}, \mathrm{P} 12 \mathrm{mg}, \mathrm{S} 0.85 \mathrm{mg}, \mathrm{Zn} 64 \mathrm{mg}$, Se $0.4 \mathrm{mg}$, Co $0.19 \mathrm{mg}$. (2) Nutrient levels.

\subsection{Measuring and Sampling}

Temperature $\left(T,{ }^{\circ} \mathrm{C}\right)$ and relative humidity $(\mathrm{RH}, \%)$ in the cowshed were measured at 8:00, 14:00 and 20:00 every day during the experiment. Electronic thermometers at the six fixed points in the cowshed were read, respectively. The temperature humidity index (THI) criteria were derived from the NRC (1971), and THI was calculated according to THI $=(1.8 \times \mathrm{T}+32)-(0.55-0.55 \times \mathrm{RH}) \times(1.8 \times \mathrm{T}-26)$, where $\mathrm{T}$ is the temperature $\left({ }^{\circ} \mathrm{C}\right)$ and $\mathrm{RH}$ is the relative humidity $(\%)$ [27]. Rectal temperature and respiratory rate were measured by animal thermometer and stopwatch respectively on the $0,4,7,11$, 14,18 and 21 days at 8:00 every day of the experiment.

Blood samples $(10 \mathrm{~mL})$ were taken from the jugular vein before morning feedings at day 0 , $4,7,11,14,18$ and 21 of the trial period and collected into tubes until coagulation. The collected samples were centrifuged at $3000 \mathrm{r} / \mathrm{min}$ for $10 \mathrm{~min}$ and $4{ }^{\circ} \mathrm{C}$, and stored at $-20{ }^{\circ} \mathrm{C}$ subsequent serum hormone and antioxidant index measurements. Insulin (INS), glucagon (GC), cortisol (COR), triiodothyronine (T3), thyroxine (T4) and heat shock protein 70 (HSP70) were detected by ELISA assay kits (Shanghai Enzyme-linked Biotechnology Co., Ltd., Shanghai, China). Superoxide dismutase (SOD), malondialdehyde (MDA), glutathione peroxidase (GSH-Px) and lactate dehydrogenase (LDH) were quantified by enzymatic colorimetry using an AV400 Clinical Analyzer (Olympus Diagnostics, Tokyo, Japan), and reagents were supplied by Jiancheng Bioengineering Institute (Nanjing, China; catalog numbers A001-1, A003-1, A005 and A020-2). All assays were performed according to manufacturer's instructions, and all serum samples were tested in triplicate.

\subsection{Metabolite Extraction and Derivatization}

All chemicals and solvents were analytical or HPLC grade. Methanol, acetonitrile, pyridine, n-hexane, methoxylamine hydrochloride, $\mathrm{N}$, and O-Bis (trimethylsilyl) trifluoroacetamide (BSTFA) with 1\% trimethylchlorosilane (TMCS) were purchased from CNW Technologies GmbH (Düsseldorf, Germany). L-2-chlorophenylalanine was from Shanghai Hengchuang Bio-technology Co., Ltd. (Shanghai, China).

Serum samples stored at $-80{ }^{\circ} \mathrm{C}$ were thawed at room temperature. A quantity of $80 \mu \mathrm{L}$ of sample was added to a $1.5 \mathrm{~mL}$ Eppendorf tube with $20 \mu \mathrm{L}$ of 2-chloro-l-phenylalanine $(0.3 \mathrm{mg} / \mathrm{mL})$ 
dissolved in methanol as internal standard, and the tube was vortexed for $10 \mathrm{~s}$. Subsequently, $240 \mu \mathrm{L}$ of ice-cold mixture of methanol and acetonitrile $(2 / 1, \mathrm{v} / \mathrm{v})$ was added, and the mixtures were vortexed for $1 \mathrm{~min}$, ultrasonicated at ambient temperature $\left(25^{\circ} \mathrm{C}\right.$ to $\left.28^{\circ} \mathrm{C}\right)$ for $5 \mathrm{~min}$, and stored at $-20^{\circ} \mathrm{C}$ for $10 \mathrm{~min}$. The extract was centrifuged at $12000 \mathrm{rpm}, 4^{\circ} \mathrm{C}$ for $10 \mathrm{~min}$. The samples were centrifuged at $12000 \mathrm{rpm}$ for $10 \mathrm{~min}$ at $4{ }^{\circ} \mathrm{C}$. A QC sample was prepared by mixing aliquots of all the samples to be a pooled sample. The inter- and intra-assay coefficients of variation were below $30 \%$. An aliquot of the $150 \mu \mathrm{L}$ supernatant was transferred to a glass sampling vial for vacuum drying at room temperature. A quantity of $80 \mu \mathrm{L}$ of $15 \mathrm{mg} / \mathrm{mL}$ methoxylamine hydrochloride in pyridine was subsequently added. The resultant mixture was vortexed vigorously for $2 \mathrm{~min}$ and incubated at $37^{\circ} \mathrm{C}$ for $90 \mathrm{~min}$. A quantity of $80 \mu \mathrm{L}$ of BSTFA (with 1\% TMCS) and $20 \mu \mathrm{L}$ n-hexane was added into the mixture, which was vortexed vigorously for $2 \mathrm{~min}$ and then derivatized at $70{ }^{\circ} \mathrm{C}$ for $60 \mathrm{~min}$. The samples were placed at ambient temperature for $30 \mathrm{~min}$ before GC-MS analysis. Chromatography analysis and identification were performed as previously described by Lu et al. (2018) [28].

\subsection{Statistic Analysis}

The experimental data were analyzed by repeated measures analysis of variance by SPSS 20.0, and data were considered statistically significant when $p<0.05$. The results of all data were expressed by Mean (+SEM).

ChemStation (version E.02.02.1431, Agilent, USA) software was used to convert the raw data (D format) to Common Data Format (CDF), and then the CDF data were imported into the ChromaTOF software (version 4.34, LECO, St Joseph, MI, USA) for data processing. Metabolites were annotated through the Fiehn or NIST database. After alignment with Statistic Compare component, the 'raw data array' (.cvs) was obtained from raw data with three dimension data sets including sample information, peak names (or retention time and $\mathrm{m} / \mathrm{z}$ ) and peak intensities. There were 728 peaks detected from all samples. In the 'data array', all internal standards and any known pseudo positive peaks (caused by background noise, column bleed or BSTFA derivatization procedure) were removed. The data was normalized to the total peak area of each sample, and multiplied by 10000 , and the peaks from the same metabolite were combined. The total detectable metabolites were 227. Data were transformed by log2 in Excel 2007 (Microsoft, USA) (use 0.000001 to replace 0 before transforming), and the resulting data matrix were then imported into SIMCA software package (14.0, Umetrics, Umeå, Sweden). Principal component analysis (PCA) and orthogonal partial least-squares discriminant analysis (OPLS-DA) were performed to visualize the metabolic difference among experimental groups, after mean centering and unit variance scaling. The Hotelling's T2 region, shown as an ellipse in score plots of the models, defines the $95 \%$ confidence interval of the modeled variation. Variable importance in the projection (VIP) ranks the overall contribution of each variable to the OPLS-DA model, and those variables with VIP $>1$ are considered relevant for group discrimination. The differential metabolites were selected on the basis of the combination of a statistically significant threshold of VIP values obtained from the OPLS- DA model and $\mathrm{p}$ values from a two-tailed Student's t-test on the normalized peak areas from different groups $(\mathrm{Z}$ vs $\mathrm{Q}, \mathrm{H}$ vs $\mathrm{Z}, \mathrm{H}$ vs $\mathrm{Q})$, where metabolites with VIP values larger than 1.0 and $\mathrm{p}$ values less than 0.05 were considered as differential metabolites. The fold change (FC) of different metabolites in the two groups was calculated. The multiple of change is the ratio of the average content of the differential metabolite in the two groups.

\section{Results}

\subsection{Environmental Temperature, Relative Humidity and Temperature and Humidity Index of Cowshed}

According to Figure 1, the environmental temperature of the cowshed varied between $33.0{ }^{\circ} \mathrm{C}$ and $35.9{ }^{\circ} \mathrm{C}$, the relative humidity varied between $48 \%$ and $70 \%$, and the THI varied between 82.36 and 88.17 during the experiment. Ingraham et al. (1974) believed that THI $<72$ had no effect on dairy cows. It would cause slight heat stress on dairy cows between 72 and 78 , moderate heat stress on dairy 
cows between 78 and 89, and severe heat stress on dairy cows above 90 [29]. Therefore, in the current experiment, dairy cows are in a state of moderate heat stress.
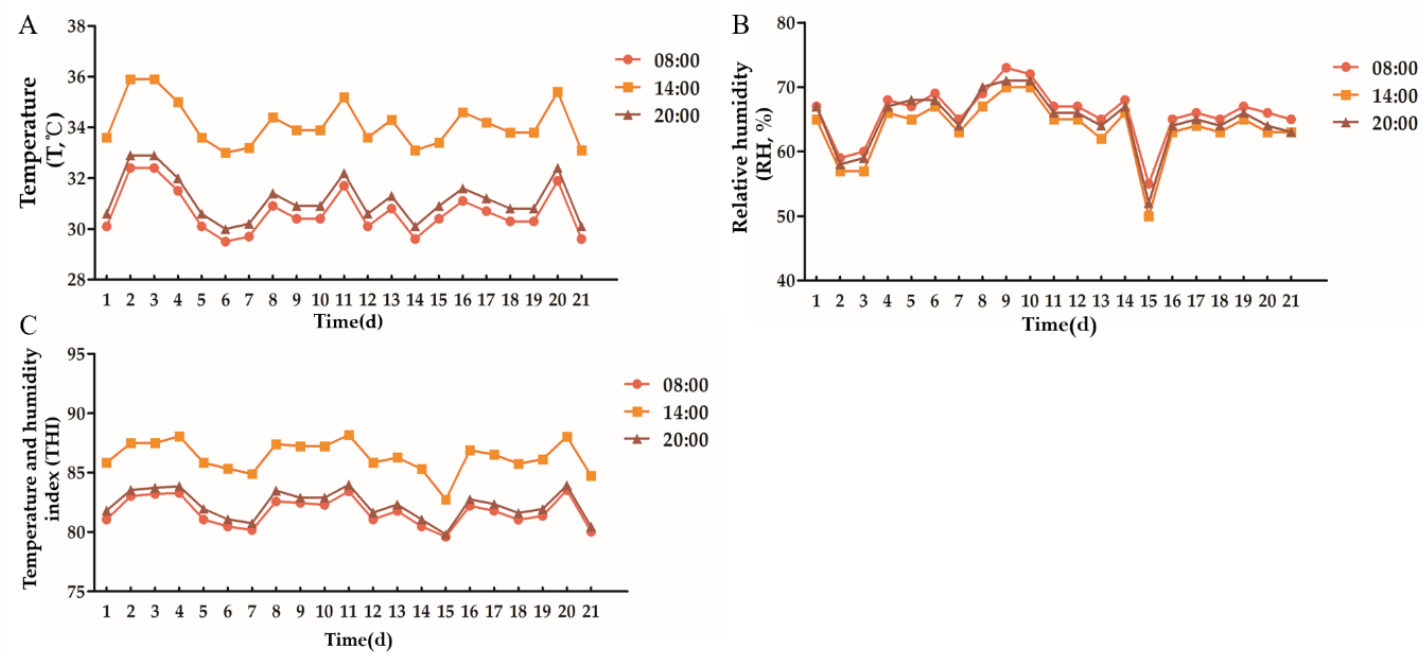

Figure 1. Environmental temperature, relative humidity and temperature and humidity index of cowshed. (A): Temperature, (B): Relative humidity, (C): Temperature and humidity index.

\subsection{Rectal Temperature and Respiratory Rate of Dairy Cows}

Table 3 shows the rectal temperature and respiratory rate of the cows during the experiment. In general, the rectal temperature of cows was $38.5^{\circ} \mathrm{C}$ in normal conditions, and the respiratory rate was 18 28 times $\cdot \mathrm{min}^{-1}$ in quiet conditions. In our experiment, the rectal temperature of dairy cows was higher than $38.5^{\circ} \mathrm{C}$, and the respiratory rate was higher than 40 times. $\mathrm{min}^{-1}$. Therefore, in the absence of other diseases, cows are in a state of heat stress.

Table 3. Rectal temperature and respiratory rate of dairy cows.

\begin{tabular}{|c|c|c|c|c|}
\hline \multirow{2}{*}{ Item } & \multirow{2}{*}{ Time(d) } & \multicolumn{3}{|c|}{ Groups } \\
\hline & & $\mathrm{CON}$ & Treatment I & Treatment II \\
\hline \multirow{7}{*}{$\begin{array}{l}\text { Rectal temperature } \\
\qquad\left({ }^{\circ} \mathrm{C}\right)\end{array}$} & 0 & $38.74 \pm 0.08$ & $38.89 \pm 0.06$ & $38.74 \pm 0.08$ \\
\hline & 4 & $39.11 \pm 0.15$ & $38.73 \pm 0.08$ & $38.80 \pm 0.07$ \\
\hline & 7 & $39.35 \pm 0.11$ & $39.04 \pm 0.06$ & $39.12 \pm 0.09$ \\
\hline & 11 & $39.25 \pm 0.09$ & $39.10 \pm 0.13$ & $38.76 \pm 0.07$ \\
\hline & 14 & $39.43 \pm 0.10$ & $39.10 \pm 0.04$ & $39.08 \pm 0.07$ \\
\hline & 18 & $39.28 \pm 0.08$ & $39.16 \pm 0.06$ & $38.88 \pm 0.08$ \\
\hline & 21 & $39.44 \pm 0.13$ & $38.85 \pm 0.06$ & $38.70 \pm 0.06$ \\
\hline \multirow{7}{*}{$\begin{array}{l}\text { Respiratory rate } \\
\left(\text { times } \cdot \mathrm{min}^{-1}\right)\end{array}$} & 0 & $47.75 \pm 2.18$ & $38.87 \pm 1.78$ & $32.38 \pm 1.93$ \\
\hline & 4 & $57.50 \pm 4.14$ & $53.50 \pm 3.54$ & $39.25 \pm 3.69$ \\
\hline & 7 & $49.88 \pm 3.80$ & $47.00 \pm 6.15$ & $45.50 \pm 5.72$ \\
\hline & 11 & $53.50 \pm 3.62$ & $45.75 \pm 3.03$ & $38.00 \pm 5.01$ \\
\hline & 14 & $62.00 \pm 8.23$ & $55.75 \pm 3.92$ & $37.25 \pm 3.54$ \\
\hline & 18 & $61.25 \pm 3.71$ & $48.75 \pm 7.77$ & $49.25 \pm 3.37$ \\
\hline & 21 & $61.25 \pm 5.25$ & $48.75 \pm 2.75$ & $47.50 \pm 5.14$ \\
\hline
\end{tabular}

\subsection{Serum Hormone, HSP70 and Antioxidant Index}

As shown in Table 4, after injection of APS, there were no significant differences in serum INS $(\mathrm{F}=0.199, p=0.950), \mathrm{GC}(\mathrm{F}=0.245, p=0.925)$, and HSP70 $(\mathrm{F}=3.440, p=0.101)$ between different time points. COR $(\mathrm{F}=6.982, p=0.026), \mathrm{T} 3(\mathrm{~F}=10.005, p=0.012)$ and $\mathrm{T} 4(\mathrm{~F}=22.530, p=0.002)$ at different time points showed significant differences. COR showed a downward trend, T3 and T4 showed an upward trend. At each time point, APS of different concentrations had no significant effect on INS 
$(\mathrm{F}=0.416, p=0.670), \mathrm{GC}(\mathrm{F}=0.443, p=0.655)$ and HSP70 $(\mathrm{F}=0.182, p=0.836)$. However, different concentrations of APS have significant effects on COR $(\mathrm{F}=30.298, p=0.000<0.05), \mathrm{T} 3(\mathrm{~F}=18.122$, $p=0.001)$, and T4 $(\mathrm{F}=44.067, p=0.000<0.05)$. Among them, APS with different concentrations had significant effects on COR on the 4th, 18th and 21st day, and had significant effect on T3 on the 11th and 14th day $(p<0.05)$. In addition, different concentrations of APS had an effect on T4 during the experimental period $(p<0.05)$. Moreover, there was no interaction between INS, GC, COR, T4 and HSP70 at different times and concentrations $(p>0.05)$, but T3 had an interaction effect on APS at different times and concentration.

As shown in Table 5, after injection of APS, there were no significant differences in serum SOD $(\mathrm{F}=0.692, p=0.652), \mathrm{MDA}(\mathrm{F}=1.239, p=0.410)$ and $\mathrm{LDH}(\mathrm{F}=3.440, p=0.101)$ between different time points. However, the injection of APS had a significant impact on GSH-Px $(\mathrm{F}=9.421, p=0.014)$ at different times, and showed a trend of rising first and then falling. At each time point, APS of different concentrations had no significant effect on SOD $(\mathrm{F}=0.468, p=0.641)$, MDA $(\mathrm{F}=0.572$, $p=0.584)$, GSH-Px $(\mathrm{F}=0.922, p=0.432)$ and LDH $(\mathrm{F}=0.182, p=0.836)$. Moreover, there was no interaction between SOD, MDA and LDH at different times and concentrations ( $p>0.05)$, but GSH-Px had an interaction effect on APS at different times and concentrations. 
Table 4. Effects of astragalus polysaccharides on serum hormone and HSP70 of heat-stressed dairy cows.

\begin{tabular}{|c|c|c|c|c|c|c|c|c|c|c|c|c|}
\hline \multirow{2}{*}{ Item } & \multirow{2}{*}{ Groups } & \multicolumn{7}{|c|}{ Time (d) } & \multirow{2}{*}{$\begin{array}{l}\text { Holistic } \\
\text { Analysis } \\
\text { (Huynh-Feldt) }\end{array}$} & \multirow{2}{*}{$\begin{array}{l}\text { Concentration } \\
(\mathbf{F}, \mathrm{P})\end{array}$} & \multirow{2}{*}{$\begin{array}{l}\text { Time } \\
(\mathrm{F}, \mathrm{P})\end{array}$} & \multirow{2}{*}{$\begin{array}{l}\text { Interaction } \\
\quad(\mathrm{F}, \mathrm{P})\end{array}$} \\
\hline & & 0 & 4 & 7 & 11 & 14 & 18 & 21 & & & & \\
\hline \multirow{3}{*}{ INS/( $\mu \mathrm{IU} / \mathrm{L})$} & CON & $20.24 \pm 2.57$ & $17.20 \pm 2.69$ & $17.14 \pm 3.11$ & $17.93 \pm 2.75$ & $15.43 \pm 2.90$ & $16.26 \pm 2.73$ & $15.85 \pm 3.28$ & \multirow{4}{*}{1.000} & \multirow{4}{*}{$0.416,0.670$} & \multirow{4}{*}{$\begin{array}{l}0.199 \\
0.950\end{array}$} & \multirow{4}{*}{$1.102,0.446$} \\
\hline & Treatment I & $17.87 \pm 4.90$ & $14.31 \pm 1.77$ & $14.38 \pm 3.06$ & $14.16 \pm 1.97$ & $16.35 \pm 3.61$ & $15.04 \pm 3.17$ & $18.84 \pm 4.03$ & & & & \\
\hline & Treatment II & $17.09 \pm 3.31$ & $16.84 \pm 2.87$ & $18.35 \pm 1.53$ & $18.49 \pm 3.53$ & $21.31 \pm 3.19$ & $16.29 \pm 2.50$ & $17.39 \pm 1.40$ & & & & \\
\hline$p$-value & & 0.321 & 0.697 & 0.856 & 0.529 & 0.621 & 0.492 & 0.492 & & & & \\
\hline \multirow{3}{*}{$\mathrm{GC} /(\mathrm{pg} / \mathrm{mL})$} & $\mathrm{CON}$ & $96.06 \pm 8.83$ & $107.31 \pm 14.52$ & $107.31 \pm 14.52$ & $122.58 \pm 13.18$ & $97.74 \pm 18.71$ & $95.54 \pm 12.73$ & $99.10 \pm 15.33$ & \multirow{4}{*}{1.000} & \multirow{4}{*}{$0.443,0.655$} & \multirow{4}{*}{$\begin{array}{l}0.245, \\
0.925\end{array}$} & \multirow{4}{*}{$2.008,0.210$} \\
\hline & Treatment I & $114.05 \pm 10.35$ & $103.95 \pm 16.06$ & $103.95 \pm 16.06$ & $104.99 \pm 17.10$ & $120.38 \pm 9.71$ & $114.95 \pm 16.12$ & $88.88 \pm 14.60$ & & & & \\
\hline & Treatment II & $103.95 \pm 15.18$ & $95.54 \pm 11.97$ & $95.54 \pm 11.97$ & $115.47 \pm 9.61$ & $108.22 \pm 7.05$ & $107.51 \pm 15.21$ & $114.82 \pm 8.14$ & & & & \\
\hline$p$-value & 0.576 & 0.838 & 0.668 & 0.487 & 0.226 & 0.407 & 0.407 & 0.576 & & & & \\
\hline \multirow{4}{*}{ COR(ng/mL) } & $\mathrm{CON}$ & $60.77 \pm 2.86$ & $57.91 \pm 2.71$ & $57.55 \pm 2.46$ & $49.97 \pm 2.21$ & $48.35 \pm 2.02$ & $48.22 \pm 3.35$ & $47.31 \pm 1.63$ & \multirow{4}{*}{1.000} & \multirow{4}{*}{$30.298,0.000$} & \multirow{4}{*}{$\begin{array}{l}6.982, \\
0.026\end{array}$} & \multirow{4}{*}{$1.976,0.216$} \\
\hline & Treatment I & $66.61 \pm 2.06$ & $57.28 \pm 2.69$ & $56.84 \pm 3.42$ & $54.01 \pm 2.98$ & $49.87 \pm 2.75$ & $53.12 \pm 1.86$ & $51.92 \pm 2.80$ & & & & \\
\hline & Treatment II & $66.04 \pm 1.65$ & $66.39 \pm 1.16$ & $60.85 \pm 1.97$ & $60.08 \pm 2.25$ & $58.90 \pm 2.61$ & $62.35 \pm 2.44$ & $62.11 \pm 2.42$ & & & & \\
\hline & & 0.184 & 0.037 & 0.135 & 0.094 & 0.068 & 0.004 & 0.004 & & & & \\
\hline \multirow{3}{*}{ T3 (nmol/L) } & CON & $2.10 \pm 0.06$ & $2.03 \pm 0.09$ & $2.03 \pm 0.09$ & $2.03 \pm 0.07$ & $2.10 \pm 0.02$ & $2.33 \pm 0.04$ & $2.32 \pm 0.08$ & \multirow{4}{*}{1.000} & \multirow{4}{*}{$18.122,0.001$} & \multirow{4}{*}{$\begin{array}{l}\text { 10.005, } \\
0.012\end{array}$} & \multirow{4}{*}{$7.338,0.015$} \\
\hline & Treatment I & $2.18 \pm 0.10$ & $2.27 \pm 0.12$ & $2.27 \pm 0.11$ & $2.23 \pm 0.03$ & $2.43 \pm 0.12$ & $2.48 \pm 0.10$ & $2.50 \pm 0.05$ & & & & \\
\hline & Treatment II & $2.10 \pm 0.05$ & $2.33 \pm 0.11$ & $2.30 \pm 0.05$ & $2.45 \pm 0.05$ & $2.80 \pm 0.07$ & $2.64 \pm 0.05$ & $2.65 \pm 0.11$ & & & & \\
\hline$p$-value & & 0.696 & 0.169 & 0.094 & 0.012 & 0.001 & 0.067 & 0.067 & & & & \\
\hline \multirow{4}{*}{$\mathrm{T} 4$ (nmol/L) } & CON & $39.53 \pm 3.95$ & $45.33 \pm 1.14$ & $37.18 \pm 2.73$ & $46.06 \pm 3.06$ & $45.50 \pm 2.50$ & $47.47 \pm 2.03$ & $48.87 \pm 2.60$ & \multirow{4}{*}{0.986} & \multirow{4}{*}{$44.067,0.000$} & & \\
\hline & Treatment I & $35.04 \pm 0.99$ & $49.92 \pm 1.98$ & $43.68 \pm 1.78$ & $54.38 \pm 2.98$ & $65.57 \pm 2.92$ & $60.00 \pm 3.69$ & $61.21 \pm 2.76$ & & & 22.530, & \\
\hline & Treatment II & $43.75 \pm 1.89$ & $55.53 \pm 2.67$ & $57.68 \pm 2.18$ & $62.14 \pm 2.34$ & $70.55 \pm 3.74$ & $67.89 \pm 3.48$ & $68.31 \pm 3.60$ & & & 0.002 & $4.302,0.052$ \\
\hline & & 0.112 & 0.019 & 0.001 & 0.009 & 0.000 & 0.004 & 0.004 & & & & \\
\hline & $\mathrm{CON}$ & $120.23 \pm 10.10$ & $113.37 \pm 6.16$ & $114.08 \pm 7.44$ & $128.58 \pm 9.50$ & $126.99 \pm 10.21$ & $120.84 \pm 6.32$ & $120.84 \pm 11.17$ & & & & \\
\hline $\mathrm{HSP70}(\mathrm{pg} / \mathrm{mL})$ & Treatment I & $104.70 \pm 5.92$ & $123.69 \pm 10.86$ & $122.65 \pm 5.16$ & $117.99 \pm 3.82$ & $113.81 \pm 9.97$ & $119.84 \pm 5.17$ & $128.03 \pm 8.54$ & & $0.182,0.836$ & 3.440, & $2.498,0.148$ \\
\hline & Treatment II & $115.08 \pm 11.49$ & $119.74 \pm 9.21$ & $121.43 \pm 7.42$ & $123.20 \pm 6.60$ & $121.77 \pm 7.89$ & $118.19 \pm 5.56$ & $113.04 \pm 5.70$ & 0.976 & $0.182,0.836$ & 0.101 & $2.498,0.148$ \\
\hline$p$-value & & 0.523 & 0.722 & 0.815 & 0.733 & 0.526 & 0.508 & 0.508 & & & & \\
\hline
\end{tabular}

Note: Global analysis uses repeated measures analysis of variance. $p<0.05$ has statistical significance (the same as below). 
Table 5. Effects of astragalus polysaccharides on serum antioxidant indexes of dairy cows.

\begin{tabular}{|c|c|c|c|c|c|c|c|c|c|c|c|c|}
\hline \multirow{2}{*}{ Item } & \multirow{2}{*}{ Groups } & \multicolumn{7}{|c|}{ Time(d) } & \multirow{2}{*}{$\begin{array}{c}\text { Holistic } \\
\text { Analysis } \\
\text { (Huynh-Feldt) }\end{array}$} & \multirow{2}{*}{$\begin{array}{l}\text { Concentration } \\
\text { (F, P) }\end{array}$} & \multirow{2}{*}{$\begin{array}{l}\text { Time } \\
(\mathrm{F}, \mathrm{P})\end{array}$} & \multirow{2}{*}{$\begin{array}{c}\text { Interaction } \\
\quad(\mathrm{F}, \mathrm{P})\end{array}$} \\
\hline & & 0 & 4 & 7 & 11 & 14 & 18 & 21 & & & & \\
\hline \multirow{4}{*}{$\mathrm{SOD} /\left(\mathrm{U} \cdot \mathrm{mL}^{-1}\right)$} & CON & $48.39 \pm 4.50$ & $38.10 \pm 4.01$ & $41.91 \pm 9.74$ & $46.48 \pm 3.30$ & $57.78 \pm 7.92$ & $43.43 \pm 10.40$ & $43.43 \pm 3.46$ & \multirow{4}{*}{1.000} & \multirow{4}{*}{$0.468,0.641$} & \multirow{4}{*}{$\begin{array}{l}0.692, \\
0.652\end{array}$} & \multirow{4}{*}{$2.886,0.115$} \\
\hline & Treatment I & $42.29 \pm 7.12$ & $56.26 \pm 8.97$ & $50.79 \pm 11.68$ & $52.20 \pm 3.91$ & $45.72 \pm 4.14$ & $41.15 \pm 7.94$ & $42.14 \pm 5.65$ & & & & \\
\hline & Treatment II & $45.84 \pm 9.38$ & $59.05 \pm 11.29$ & $50.80 \pm 4.77$ & $52.32 \pm 4.77$ & $33.53 \pm 7.74$ & $52.32 \pm 12.67$ & $50.11 \pm 4.22$ & & & & \\
\hline & & 0.738 & 0.231 & 0.602 & 0.709 & 0.092 & 0.737 & 0.737 & & & & \\
\hline \multirow{4}{*}{$\mathrm{MDA} /\left(\mathrm{nmol} \cdot \mathrm{mL}^{-1}\right)$} & $\mathrm{CON}$ & $2.27 \pm 0.34$ & $1.80 \pm 0.26$ & $3.14 \pm 0.37$ & $3.90 \pm 0.45$ & $4.42 \pm 0.55$ & $3.17 \pm 0.38$ & $3.31 \pm 0.90$ & \multirow{4}{*}{0.468} & \multirow{4}{*}{$0.572,0.584$} & \multirow{4}{*}{$\begin{array}{l}1.239, \\
0.410\end{array}$} & \multirow{4}{*}{$1.789,0.249$} \\
\hline & Treatment I & $2.62 \pm 0.50$ & $3.02 \pm 0.78$ & $2.10 \pm 0.24$ & $3.90 \pm 1.10$ & $2.56 \pm 0.46$ & $3.85 \pm 0.57$ & $6.40 \pm 1.07$ & & & & \\
\hline & Treatment II & $2.27 \pm 0.11$ & $2.91 \pm 0.31$ & $1.98 \pm 0.58$ & $3.60 \pm 0.38$ & $2.21 \pm 0.23$ & $3.13 \pm 0.41$ & $4.48 \pm 0.75$ & & & & \\
\hline & & 0.741 & 0.230 & 0.405 & 0.949 & 0.212 & 0.445 & 0.445 & & & & \\
\hline \multirow{4}{*}{ GSH-Px/(U.mL $\left.{ }^{-1}\right)$} & $\mathrm{CON}$ & $545.45 \pm 63.03$ & $604.36 \pm 48.11$ & $516.00 \pm 41.99$ & $583.64 \pm 73.78$ & $520.37 \pm 34.32$ & $540.62 \pm 38.94$ & $507.27 \pm 56.17$ & \multirow{4}{*}{0.647} & \multirow{4}{*}{$0.922,0.432$} & \multirow{4}{*}{$\begin{array}{l}9.421, \\
0.014\end{array}$} & \multirow{4}{*}{$4.913,0.039$} \\
\hline & Treatment I & $562.91 \pm 79.35$ & $569.45 \pm 58.56$ & $690.55 \pm 37.03$ & $744.00 \pm 66.38$ & $502.91 \pm 36.58$ & $614.02 \pm 27.04$ & $614.18 \pm 45.75$ & & & & \\
\hline & Treatment II & $580.36 \pm 46.42$ & $597.82 \pm 60.39$ & $524.73 \pm 51.42$ & $722.18 \pm 33.07$ & $427.64 \pm 29.69$ & $563.07 \pm 25.91$ & $544.36 \pm 53.73$ & & & & \\
\hline & & 0.930 & 0.897 & 0.065 & 0.182 & 0.793 & 0.768 & 0.768 & & & & \\
\hline \multirow{4}{*}{$\mathrm{LDH} /\left(\mathrm{U} \cdot \mathrm{L}^{-1}\right)$} & CON & $433.75 \pm 27.16$ & $371.69 \pm 16.03$ & $428.92 \pm 23.69$ & $414.16 \pm 17.04$ & $447.59 \pm 24.32$ & $491.27 \pm 13.66$ & $451.55 \pm 33.24$ & \multirow{4}{*}{0.976} & \multirow{4}{*}{$0.182,0.836$} & \multirow{4}{*}{$\begin{array}{l}3.440, \\
0.101\end{array}$} & \multirow{4}{*}{$2.498,0.148$} \\
\hline & Treatment I & $334.14 \pm 24.26$ & $519.28 \pm 26.24$ & $462.95 \pm 22.24$ & $515.94 \pm 19.17$ & $460.64 \pm 27.49$ & $495.18 \pm 15.35$ & $465.18 \pm 23.45$ & & & & \\
\hline & Treatment II & $429.22 \pm 25.96$ & $433.13 \pm 22.48$ & $385.84 \pm 24.08$ & $454.52 \pm 9.77$ & $446.98 \pm 20.90$ & $456.02 \pm 10.44$ & $451.66 \pm 16.66$ & & & & \\
\hline & & 0.349 & 0.298 & 0.561 & 0.940 & 0.957 & 0.542 & 0.542 & & & & \\
\hline
\end{tabular}




\subsection{Metabolomics Analysis of Dairy Cow Serum}

A total of 227 metabolites were identified by GC-MS. Metabonomic data were imported into the SIMCA software package (14.0, Umetrics, Umeå, Sweden). As shown in Figure 2A, the PCA model shows that all samples are basically within the $95 \%$ confidence interval. There is a trend of separation among the three groups of samples. Because of individual differences between samples, the results of principal component analysis are not completely separated, indicating that the constructed model is stable and reliable. In order to further obtain the metabolic differences between the two groups, the PCA scores of the two groups were compared with those of the mid-test and pre-test ( $Z$ vs Q), post-test and mid-test (H vs Z), and post-test and pre-test (H vs Q), as shown in Figure 2B-D. Comparing the two groups of samples, there is a trend of separation, and there is no overlap between the three groups. Therefore, the current PCA model can be used to explain the metabolic differences between the two groups more reliably.

In order to obtain more reliable differential metabolite analysis and filter signals unrelated to model classification, an OPLS-DA model was obtained by using OPLS-DA between $Z$ vs $Q, H$ vs $Z$ and $H$ vs Q groups, and RPT with 200 responses was used. The parameters of each model are shown in Table 6. In the RPT test, $\mathrm{Q}^{2}$ should be less than zero under normal conditions. Both $\mathrm{R}^{2}$ and $\mathrm{Q}^{2}$ suggested that the model was effective. As shown in Figure 3A,C,E, the two groups of samples were separated on the OPLS-DA scores plots, which shows that the current model can explain the differences between groups very well. Therefore, the above pattern discrimination can be used for the screening of potential biomarkers.

Table 6. OPLS-DA model parameter list.

\begin{tabular}{llccccc}
\hline Groups & $\mathbf{N}$ & $\mathbf{R}^{\mathbf{2}} \mathbf{X}(\mathbf{c u m})$ & $\mathbf{R}^{\mathbf{2}} \mathbf{Y}($ cum) & $\mathbf{Q}^{\mathbf{2}}$ (cum) & $\mathbf{R}^{\mathbf{2}}$ & $\mathbf{Q}^{\mathbf{2}}$ \\
\hline Z vs Q & 10 & 0.407 & 0.956 & 0.449 & 0.883 & -0.447 \\
H vs Z & 10 & 0.312 & 0.985 & 0.609 & 0.934 & -0.298 \\
H vs Q & 10 & 0.544 & 0.999 & 0.795 & 0.978 & -0.110 \\
\hline
\end{tabular}

Note: The number of principal components in modeling. N: number of samples. $R^{2} X($ cum): cumulative interpretation rate of the model in the $\mathrm{X}$-axis direction when modeling multivariate statistical analysis. cum: the cumulative result of several principal components. $R^{2} Y(\mathrm{cum})$ : cumulative interpretation rate of the model in the Y-axis direction. $\mathrm{Q}^{2}$ (cum): cumulative prediction rate of the model. $\mathrm{R}^{2}, \mathrm{Q}^{2}$ : The parameters of the response sort test are used to measure whether the model is over-fitting.
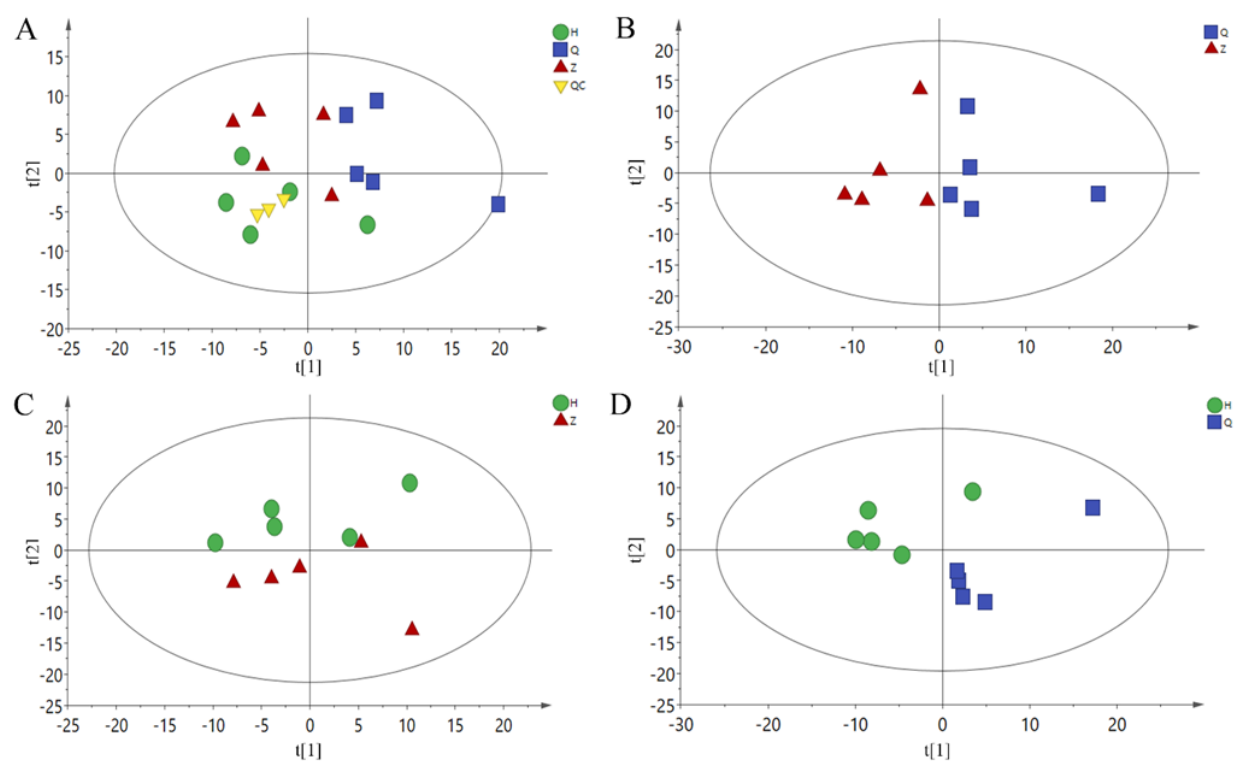

Figure 2. PCA Scores plot. (A): All-PCA Scores plot, (B): Z vs Q PCA Scores plot, (C): H vs Z PCA Scores plot, (D): H vs Q PCA Scores plot. Q: Pre-test, Z: Mid-test, H: Post-test, QC: quality control. 
A
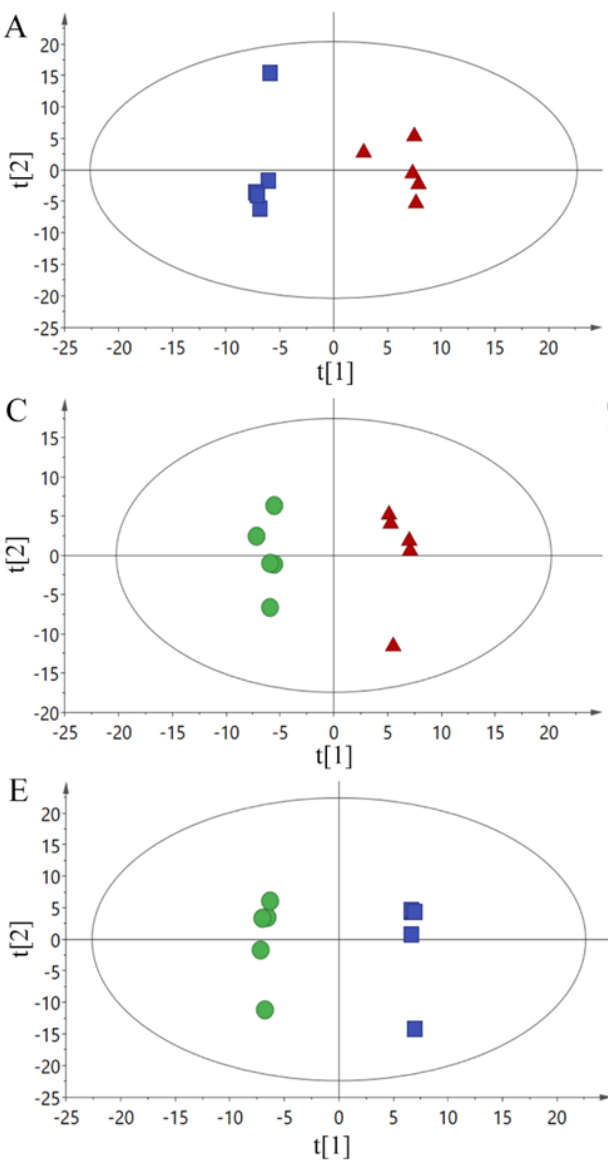

$\mathrm{n}_{2}^{\circ} \mathrm{B}$

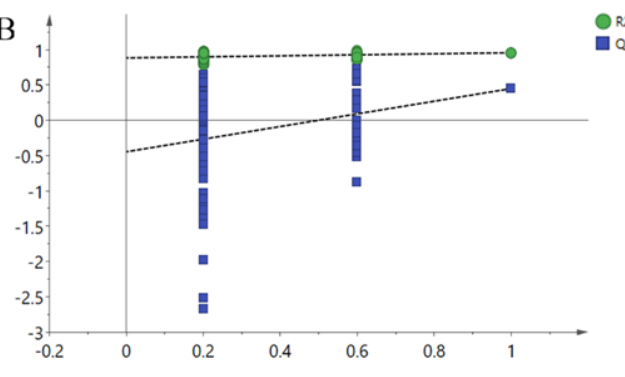

${ }_{\Delta=}^{-1} \mathrm{D}$

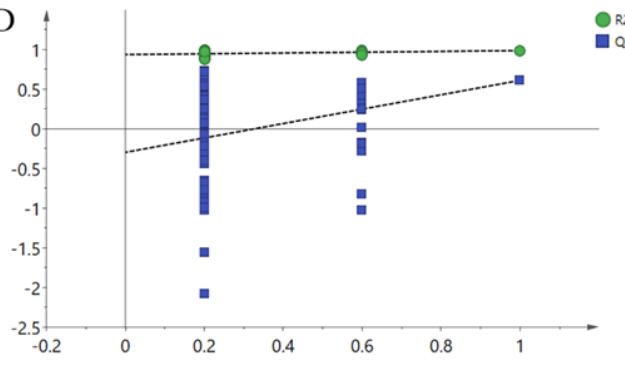

$a_{0}^{+} \mathrm{F}$

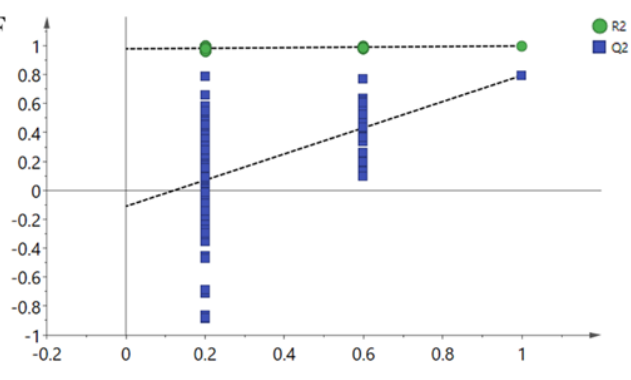

Figure 3. OPLS-DA scores plots and permutation test plots. (A): $Z$ vs Q PLS-DA Scores plot, (B): $\mathrm{H}$ vs Z PLS-DA scores plot, (C): $\mathrm{H}$ vs Q PLS-DA scores plot. (D): Z vs Q permutation test plots, (E): H vs Z permutation test plots, (F): H vs Q permutation test plots. Q: Pre-test, Z: Mid-test, H: Post-test.

\subsection{Screening of Differential Metabolites}

The metabolites were assigned according to the Fiehn database, and the FC values of the differential metabolites in the two groups were calculated. After $\log 2$ conversion, $\log 2 \mathrm{FC}>0$ indicates upregulation and $\log 2 \mathrm{FC}<0$ indicates downregulation. As shown in Figure $4 \mathrm{~A}-\mathrm{C},-\log 10$ ( $p$-value) is from the original $p$-value calculated from the differential metabolites. $-\log 10(0.05)=1.30 .-\log 10(p$-value $)>$ 1.30 means significant difference. The red dot indicates $\log 2 \mathrm{FC}>0$, and the metabolite is upregulated. The blue dot indicates $\log 2 \mathrm{FC}<0$, and the metabolite is downregulated. The gray dot means no significant difference $(-\log 10(p$-value $)<1.3)$. As shown in Figure $4 \mathrm{D}$, a total of 31 differential metabolites were obtained between the mid-test and pre-test, 47 differential metabolites were observed between the post-test and mid-test, and 34 differential metabolites were detected between the post-test and pre-test. 

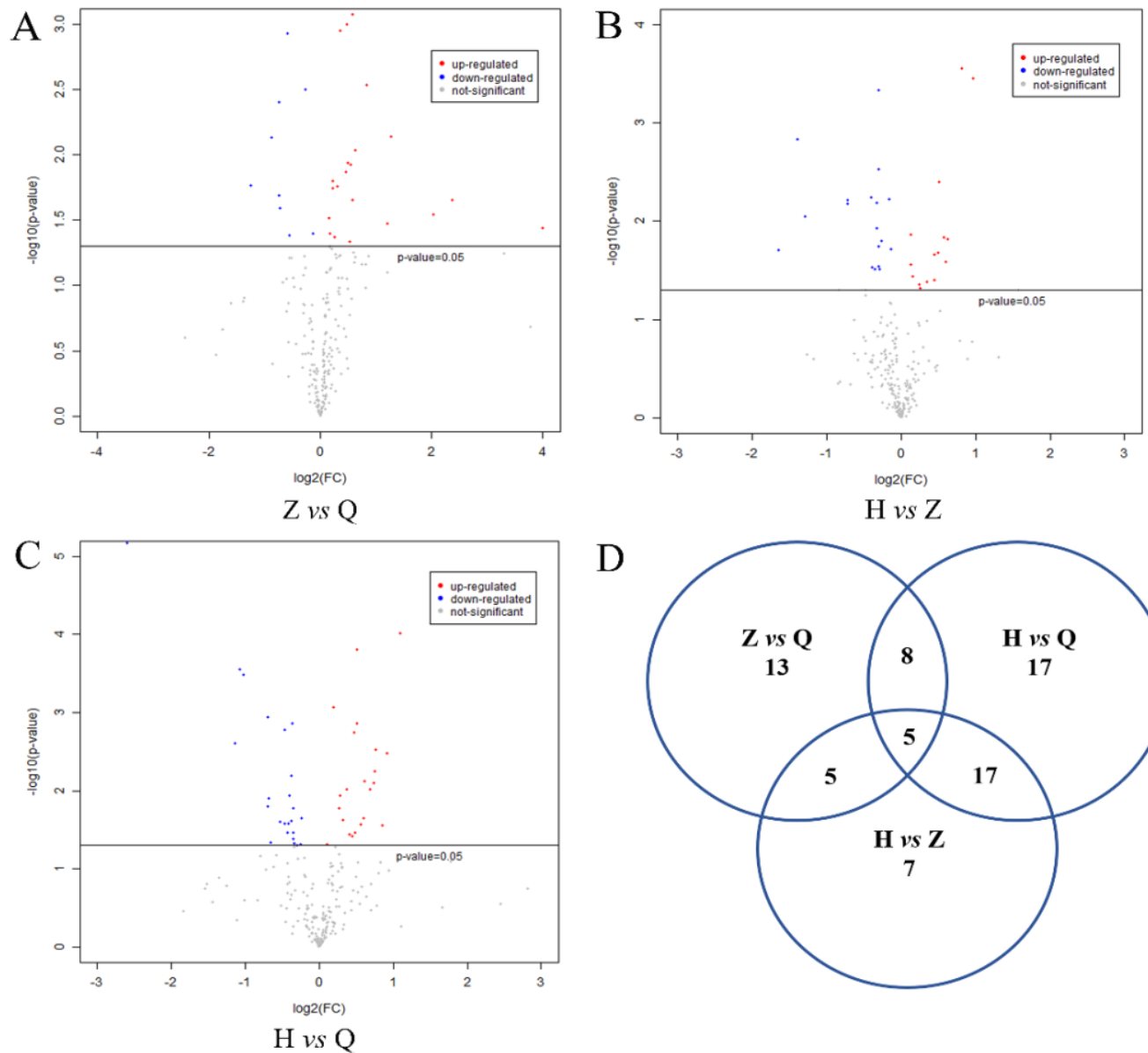

$\mathrm{D}$

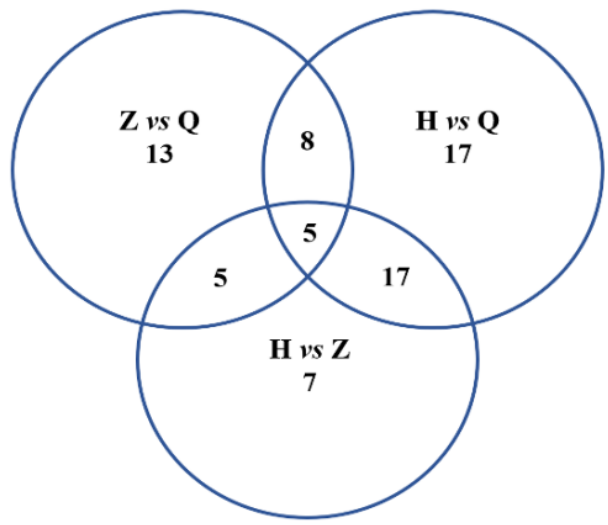

Figure 4. Expression of differential metabolites in serum of dairy cows and Venn diagram. Note: (A-C) were volcanic plots of $Z$ vs $Q, H$ vs $Z$ and $H$ vs $Q$, respectively. $-\log 10$ ( $p$-value) is from the original $p$-value calculated from the differential metabolites. $-\log 10(0.05)=1.30-\log 10(p$-value $)>1.30$ means significant difference. The red dot indicates $\log 2 \mathrm{FC}>0$, and the metabolite is upregulated. The blue dot indicates $\log 2 \mathrm{FC}<0$, and the metabolite is downregulated. The gray dot means no significant difference $(-\log 10$ ( $p$-value $)<1.3)$. (D) is the Ven diagram of the difference variables between groups.

\subsection{Identification and Comparison of Differential Metabolites}

In this study, we selected 20 different metabolites with biomarkers in cow serum; their retention time, quant mass and classification are shown in Table 7, and their peak areas are shown in Figure 5. Among these metabolites, glucose-1-phosphate, glutamine, glycerol-1-phosphate, glycine, lysine, pyrophosphoric acid, putrescine, tryptophan, and tyrosine were upregulated before and after the test. 2-picolinic acid, 3-aminoisobutyric acid, alanine, $\gamma$-aminobutyric acid, glucose, sugar alcohol, nicotinamide, norvaline, and phenylacetic acid were downregulated before and after the test. Catechol and methylamine showed a downward trend after being upregulated after injection of APS. As shown in Figure 6, in order to more intuitively and clearly understand the changes of 20 differential metabolites in dairy cow serum, cluster analysis was performed on the peak area. 
Table 7. Identification and screening of serum differential metabolites of dairy cows.

\begin{tabular}{|c|c|c|c|c|c|c|}
\hline Metabolite name & Classification & Retention Time (min) & Quant Mass & $\mathrm{Z}$ vs $\mathrm{Q}$ & $\mathrm{H}$ vs $\mathrm{Z}$ & H vs $Q$ \\
\hline 2-Picolinic Acid & Organic acid & 6.28 & 136 & ns & $\downarrow \downarrow \downarrow$ & $\downarrow$ \\
\hline 3-Aminoisobutyric Acid & Organic acid & 9.38 & 102 & ns & $\downarrow \downarrow$ & $\downarrow \downarrow \downarrow$ \\
\hline Alanine & Amino acid & 7.48 & 116 & ns & $\downarrow$ & $\downarrow$ \\
\hline Catechol & Amine & 11.4 & 254 & $\downarrow$ & $\uparrow$ & ns \\
\hline Gamma-Aminobutyric Acid & Organic acid & 9.38 & 102 & ns & $\downarrow \downarrow$ & $\downarrow \downarrow \downarrow$ \\
\hline Glucose & Carbohydrate & 23.64 & 319 & ns & ns & $\downarrow \downarrow$ \\
\hline Glucose-1-Phosphate & Carbohydrate & 17.59 & 274 & $\uparrow$ & ns & ns \\
\hline Glutathione & Organic acid & 8.63 & 282 & $\uparrow$ & $\uparrow$ & $\uparrow \uparrow \uparrow$ \\
\hline Glycerol-1-Phosphate & Organic acid & 18.36 & 191 & ns & ns & $\uparrow \uparrow \uparrow$ \\
\hline Glycine & Amino acid & 11.18 & 174 & $\uparrow \uparrow$ & ns & $\uparrow \uparrow$ \\
\hline Lysine & Amino acid & 24.15 & 174 & $\uparrow \uparrow$ & ns & $\uparrow \uparrow$ \\
\hline Lyxitol & Carbohydrate & 20.11 & 305 & $\downarrow$ & ns & $\downarrow$ \\
\hline Methylamine & Amine & 15.68 & 176 & $\downarrow$ & $\uparrow$ & ns \\
\hline Nicotianamine & Alkaloid & 7.54 & 187 & ns & $\downarrow$ & $\downarrow$ \\
\hline Norvaline & Amino acid & 12.93 & 144 & ns & $\downarrow$ & $\downarrow$ \\
\hline Phenylacetic Acid & Organic acid & 11.09 & 91 & $\downarrow \downarrow$ & $\downarrow \downarrow \downarrow$ & ns \\
\hline Pyrophosphate & Inorganic acid & 18.73 & 451 & ns & $\uparrow$ & $\uparrow \uparrow \uparrow$ \\
\hline Putrescine & Amine & 13.76 & 174 & $\uparrow \uparrow$ & $\uparrow$ & $\uparrow \uparrow \uparrow$ \\
\hline Tryptophan & Amino acid & 28.8 & 202 & $\uparrow \uparrow$ & ns & $\uparrow \uparrow \uparrow$ \\
\hline Tyrosine & Amino acid & 24.46 & 218 & $\uparrow$ & ns & $\uparrow$ \\
\hline
\end{tabular}

Note: $\uparrow$ significant upregulation, $\downarrow$ significant downregulation, ns: not significant, $\uparrow: p<0.05, \uparrow \uparrow: p<0.01, \uparrow \uparrow \uparrow:$ $p<0.001$.

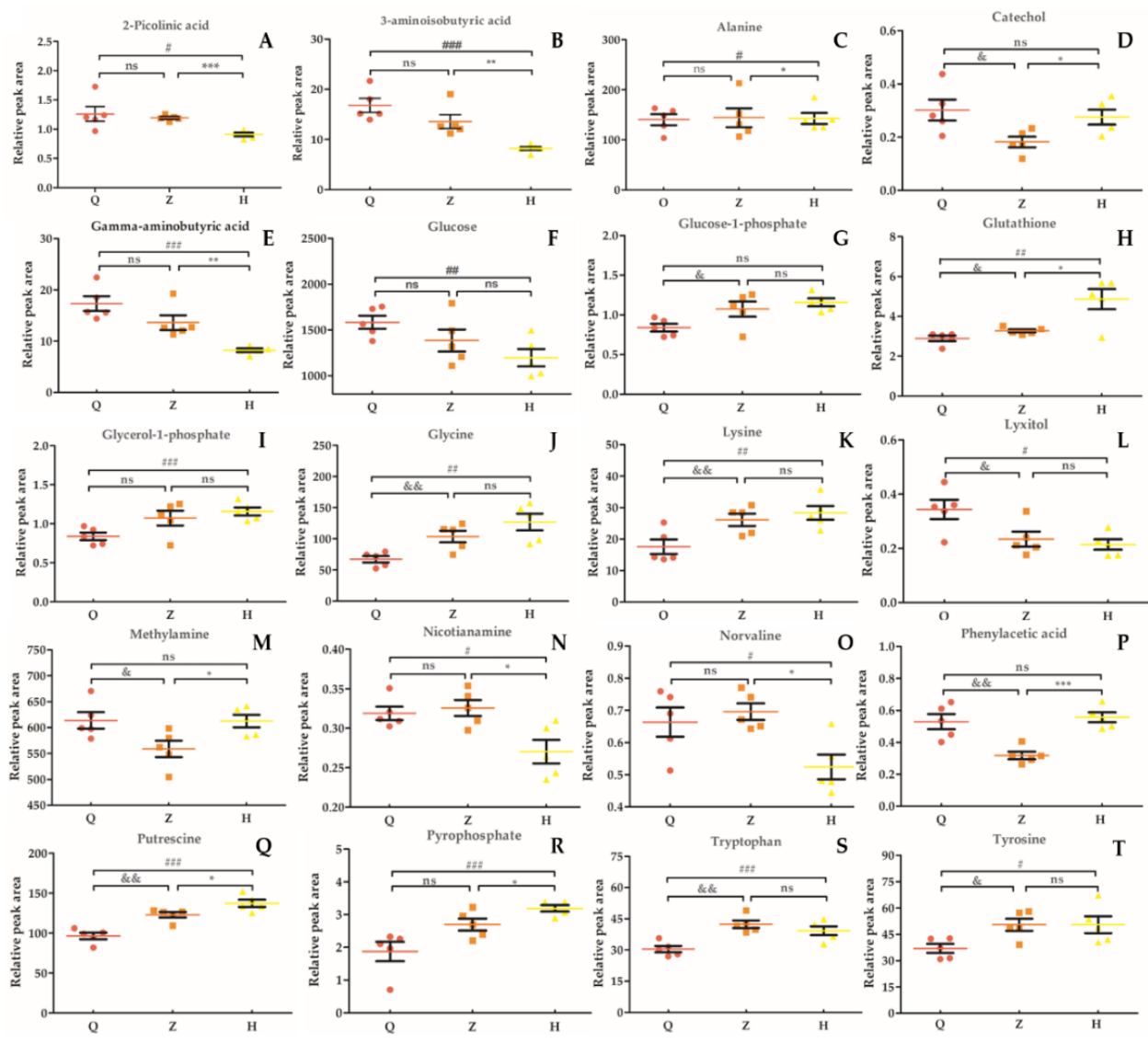

Figure 5. Relative peak area of serum marker metabolites in dairy cows. (A): 2-Picolinic acid. (B): 3-Aminoisobutyric acid. (C): Alanine. (D): Catechol. (E): Gamma-aminobutyric acid. (F): Glucose. G: Glucose-1-phosphate. (H): Glutathione. (I): Glycerol-1-phosphate. (J): Glycine. (K): Lysine. (L): Lyxitol. (M): Methylamine. (N): Nicotianamine. (O): Norvaline. (P): Phenylacetic acid. (Q): Putrescine. (R): Pyrophosphate. (S): Tryptophan. (T): Tyrosine. "\&" means Z vs Q significant difference $(p<0.05)$, “*” means H vs Z significant difference $(p<0.05)$, “\#” means H vs Q significant difference $(p<0.05)$; "ns" means the difference is not significant $(p>0.05)$. 


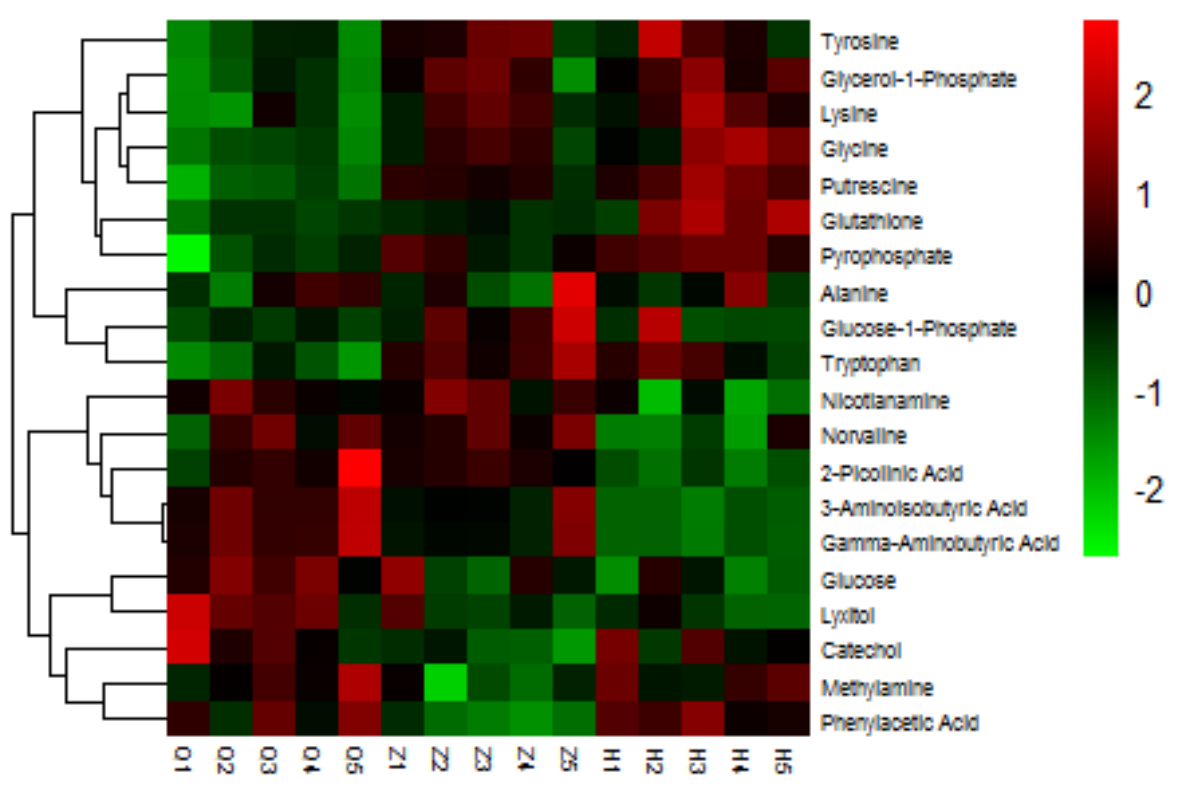

Figure 6. Heat map of serum differential metabolites in dairy cows. Changes in color represent changes in relative peak area, where red represents increased serum metabolite content and blue represents decreased serum metabolite content.

\subsection{Differential Metabolite Metabolic Pathway}

To further study the biomarkers, we obtained 20 biomarkers' KEGG IDs ((Kyoto encyclopedia of genes and genomes identifications) and enriched the serum potential biomarkers of dairy cows by MBROLE (Metabolites biological role) pathway analysis. As shown in Figure 7, according to $p<0.05$ in metabolic pathway, the enrichment map of metabolic pathway is drawn with the name of metabolic pathway as abscissa and $-\log (p$-value) as ordinate. The metabolic pathways with $-\log (p)>1.5$ are considered the most relevant pathways involved in the conditions under experiment. Among these pathways, biological modules were involved in sugar metabolism, protein metabolism, nucleotide metabolism and vitamin metabolism. These include protein digestion and absorption, glutamine metabolism, the prolactin signaling pathway, aminoacyl-tRNA biosynthesis, pentose and glucuronate interconversions, the glucagon signaling pathway, glycolysis/gluconeogenesis, thiamine metabolism, phenylalanine, tyrosine and tryptophan biosynthesis, galactose metabolism, the insulin signaling pathway, and glycine, serine and threonine metabolism, etc. Hence, five metabolic pathways were selected as potential metabolic pathways for APS, affecting serum metabolism of heat-stressed cows (Table 8). 


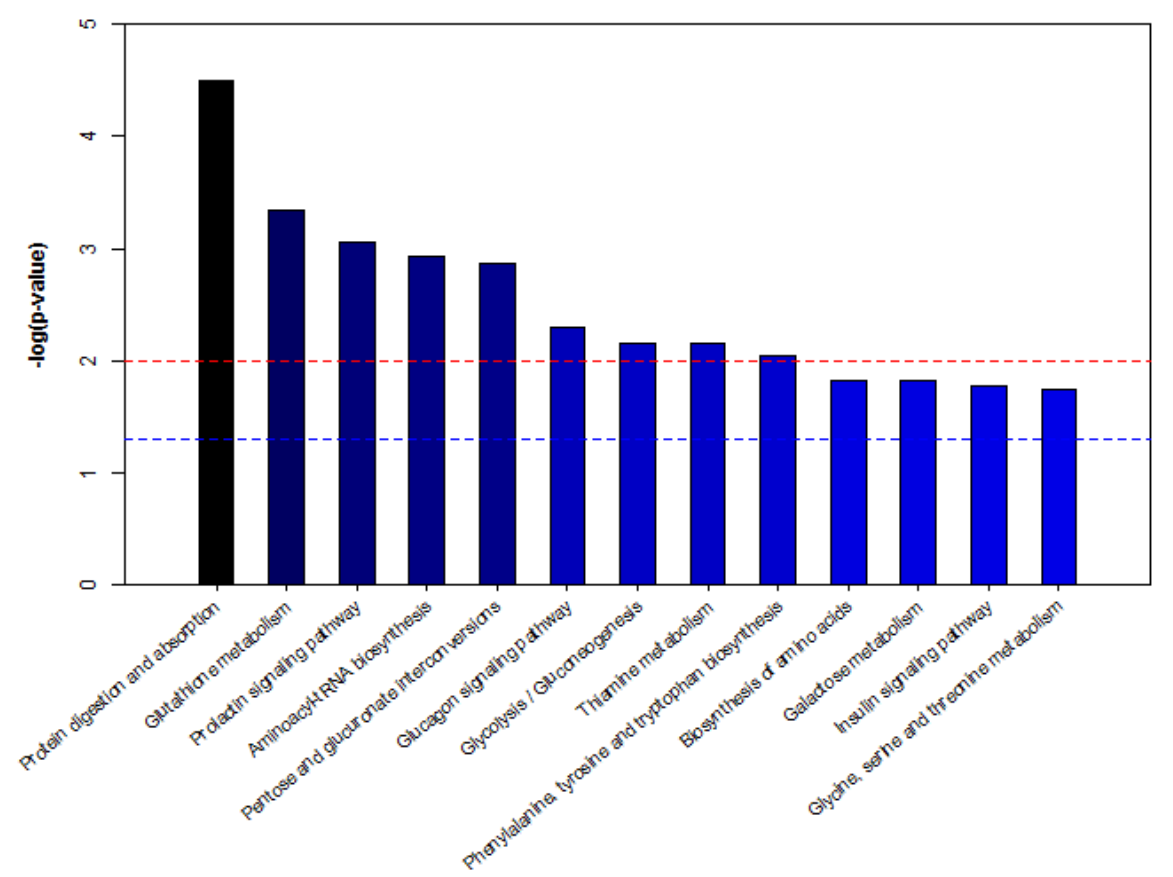

Figure 7. Pathway analysis of metabolites from dairy cows' serum. Note: $-\log (p)$ is from the original $p$-value calculated from the enrichment analysis. The red line indicates $p=0.01$, and the blue line indicates $p=0.05$. When the column top is higher than the blue line or the red line, the signal path is significant.

Table 8. The detailed results of potential metabolic pathways.

\begin{tabular}{ccc}
\hline Potential Metabolic Pathway & $-\log (p)$ & Relevant Metabolites \\
\hline Protein digestion and absorption & 4.49 & glucose, glycine, tryptophan, tyrosine \\
Glutathione metabolism & 3.34 & glycine, glutathione, putrescine \\
Pentose and glucuronate interconversions & 2.87 & glucose-1-phosphate, lyxitol \\
Glycolysis / Gluconeogenesis & 2.15 & glucose, glucose-1-phosphate \\
Biosynthesis of amino acids & 1.83 & glycine, tryptophan, tyrosine \\
\hline
\end{tabular}

Note: $-\log (p)$ is from the original $p$-value calculated from the enrichment analysis.

\section{Discussion}

Recently, APS has drawn extensive attention because of its immunity, antiviral, hypoglycemic, and antioxidant properties [30-32]. However, the mechanism of application in heat-stressed dairy cows is not known. Generally, heat stress not only reduces growth, reproductive efficiency, milk yield, and milk quality [33], but also affects the hormone metabolism of dairy cows [34]. COR is a stress hormone secreted by the adrenal cortex. In this study, the level of COR in the experimental group increased after APS injection. Christison et al. (1972) proved that the plasma COR of dairy cows increased significantly in a state of acute heat stress. However, the short- and long-term environmental heat effects on COR are clear, with initial increases due to acute stressors and a decline of amounts in plasma levels after prolonged exposure to stressors [35]. Furthermore, the secretion of COR is closely related to milk production and physiological metabolism compensation [36], which may have led to our results. T3 and T4 are secreted by the thyroid gland and its peripheral tissues. The cell signals mediated by T3 and T4 play a key role in regulating body temperature, energy intake, and metabolism [37]. When the body is exposed to a thermal environment, its basic metabolic rate and heat production will be reduced, and the synthesis and secretion of T3 and T4 in the thyroid of dairy cows will be reduced [38]. Our results showed that T3 and T4 levels increased significantly after APS injection. This might be because APS can recover the metabolism of dairy cows by increasing the concentration of T3 and T4, and alleviating the heat stress of dairy cows. Previous studies revealed that a Chinese 
herbal medicine additive can increase the concentration of T3 and T4 in the serum of heat-stressed cows, reduce the concentration of COR and adrenocorticotropic hormone, and alleviate heat stress by regulating the serum hormones and enzymes of cows [39]. This result was in accordance with the present results on T3 and T4. Moreover, in this study, our results showed that APS had no significant effect on INS and GC in heat-stressed dairy cows. Generally, heat stress results in higher insulin secretion in lactating cows [40]. Research has shown that dietary supplementation with traditional Chinese medicine can reduce the serum glucose level and increase the apparent nutrient digestibility of heat-stressed beef cattle [41]. However, adding Chinese herbal medicine to a basic diet improves the serum glucose level of chickens under heat stress conditions [42]. These results may be related to the secretion of insulin and glucagon in different states. Our results showed that APS had no effect on the secretion of insulin and glucagon under heat stress. This may be related to the intake and milk production of cows.

Additionally, the production rate of oxygen free radicals is higher than the clearance rate due to the high metabolic rate of cows under heat stress conditions, especially in lactating cows. Consequently, the antioxidative function of dairy cows was decreased [43]. In present study, the results showed that APS had no significant effect on the serum antioxidant index of dairy cows. However, APS also did not cause an abnormal antioxidant index. This may be due to the long-term heat stress state of dairy cows, and its antioxidant level may have reached a balance, but the injection of APS in a short time is not sufficient to change its serum antioxidant level. HSP70 also has no significant effect and may be caused by the above reasons. Although astragalus as an adjunctive treatment to conventional therapies was found to offer some promising effects in serum components, suboptimal methodological quality and poor reporting meant that definitive conclusions could not be made based on available evidence [44].

In order to analyze the effects of APS on the metabolism of heat-stressed dairy cows, the metabolomics method based on GC-MS was used to determine the changes in serum. Our results showed that 294 metabolites were detected in the serum of dairy cows. After PCA analysis and OPLS-DA analysis, 20 biomarkers were identified, and the comparison among groups was statistically significant. These biomarkers are mainly involved in the metabolism of serum sugar, amino acids, and vitamins in dairy cows. They are potential markers the effects of APS on dairy cows.

In our study, glucose-1-phosphate was upregulated, and 3-aminoisobutyric acid, glucose, and glycol were downregulated in the serum of dairy cows after APS injection, and catechol was significantly increased after APS injection. Previous studies have shown that APS is particularly prominent in the treatment of diabetes mellitus, and it is a candidate for insulin resistance therapy [45,46]. Glucose-1-phosphate is the substrate of glycosyl derivatives [47], and it is also an important glycogen synthesized by liver and muscle in adrenal dysfunction [48]. $\beta$-aminoisobutyric acid, also known as DL-3-aminoisobutyric acid, is produced in skeletal muscle during exercise. The study has shown that $\beta$-aminoisobutyric acid plays a role in diabetes [49]. It has also been confirmed that $\beta$-aminoisobutyric acid can attenuate lipopolysaccharide-induced inflammation and insulin resistance in adipocytes through AMP-activated protein kinase-mediated pathways [50]. Catechol belongs to the catecholamines and is a precondition for the synthesis of epinephrine and norepinephrine [51]. Heat stress can significantly increase the levels of serum adrenaline and noradrenaline levels [52]. Moreover, in a study of compensatory changes in glucose production and utilization after insulin administration, it was found that acute glucocorticoid is glucagon and catecholamine. When glucagon secretion is impaired, the adrenergic mechanism, especially adrenomedullary adrenaline, is essential for recovery from hypoglycemia [53]. Therefore, our results show that these substances may affect the level of serum glucose metabolism in dairy cows by affecting the glycolysis/gluconeogenesis process, insulin signaling pathway and glucagon signaling pathway. Thus, this alleviates the imbalance of energy metabolism caused by heat stress in dairy cows.

In addition, after APS injection, serum glutamine, glycine, lysine, tryptophan and tyrosine were upregulated. However, alanine and valine were downregulated in the current study. Alanine, glutamine, glycine, and proline are all raw sugar amino acids, lysine is a ketogenic amino acid, 
and tryptophan and tyrosine are raw sugar ketone amino acids. According to a previous study, after $24 \mathrm{~h}$ of discontinuation of insulin administration, the levels of alanine, glycine and threonine in the arteries of diabetic patients decreased, but the levels of valine, leucine and isoleucine increased [54]. Moreover, the serum levels of valine, alanine, tyrosine and tryptophan in type 2 diabetes mellitus patients were increased by using serum metabonomics [55]. Therefore, our results further prove that APS can regulate the amino acid metabolism pathway, intervene in the metabolic disorder of cows under stress, and reduce the physiological effect of stress in the summer.

$\gamma$-Aminobutyric acid (GABA) is an inhibitory neurotransmitter produced by the central nervous system, which affects energy metabolism in the brain [56]. The results showed that the addition of rumen-protective GABA (RP-GABA) to beef cattle's diet could significantly increase the average daily intake of heat-stressed beef cattle, and improve the nutritional digestibility, growth performance and antioxidant capacity of heat-stressed beef cattle [57]. Nicotinamide is an amide form of nicotinic acid (vitamin B3), which participates in cell proliferation and differentiation [58] and energy metabolism [59] and can improve energy metabolism diseases [60]. Additionally, inducing the use of pyrophosphate (PPI) as an energy enzyme to replace the use of ATP is a potential strategy to deal with the energy crisis [61]. Our study showed that GABA and nicotinamide were downregulated and pyrophosphate was upregulated after APS injection. Therefore, APS plays an important role in the energy metabolism of heat-stressed dairy cows.

\section{Conclusions}

In summary, the current results showed that APS had a significant effect on the levels of COR, T3 and T4 in dairy cows' serum under heat stress. After APS injection, glucose-1-phosphate, glutamine, glycerol-1-phosphate, glycine, lysine, pyrophosphoric acid, putrescine, tryptophan, and tyrosine were upregulated. 2-picolinic acid, 3-aminoisobutyric acid, alanine, $\gamma$-aminobutyric acid, glucose, sugar alcohol, nicotinamide, norvaline, and phenylacetic acid were downregulated. Catechol and methylamine showed a downward trend after being upregulated after injection of APS. Consequently, APS regulates the energy metabolism of heat stressed dairy cows through glucose metabolism and amino acid metabolism.

Author Contributions: Conceived and design the experiment: the work was conceived by H.Z. and Y.X.; performed the experiment, H.Z. and Y.L.; analyzed the data, H.Z., Y.L. and L.Z.; contributed reagents/materials/analysis tools, H.Z., Y.L. and Z.W.; manuscript writing, H.Z.; reviewed and approved the manuscript, H.Z., Y.X., Y.L., Z.W., L.Z. and Z.H. All authors have read and agreed to the published version of the manuscript.

Funding: This research was supported by the earmarked fund for Jiangsu Agricultural Industry Technology System (JATS [2018] 291).

Acknowledgments: The authors are grateful to all members of the institute of dairy science for their contributions to sample determination. This research was supported by the earmarked fund for Jiangsu Agricultural Industry Technology System (JATS [2018] 291).

Conflicts of Interest: The authors declare no conflict of interest.

$\begin{array}{ll}\text { Abbreviations } \\ \text { APS } & \text { Astragalus polysaccharides } \\ \text { COR } & \text { Cortisol } \\ \text { T3 } & \text { Triiodothyronine } \\ \text { T4 } & \text { Thyroxine } \\ \text { INS } & \text { Insulin } \\ \text { GC } & \text { Glucagon } \\ \text { HSP70 } & \text { Heat shock protein 70 } \\ \text { SOD } & \text { Superoxide dismutase } \\ \text { MDA } & \text { Malondialdehyde } \\ \text { GSH-Px } & \text { Glutathione peroxidase }\end{array}$




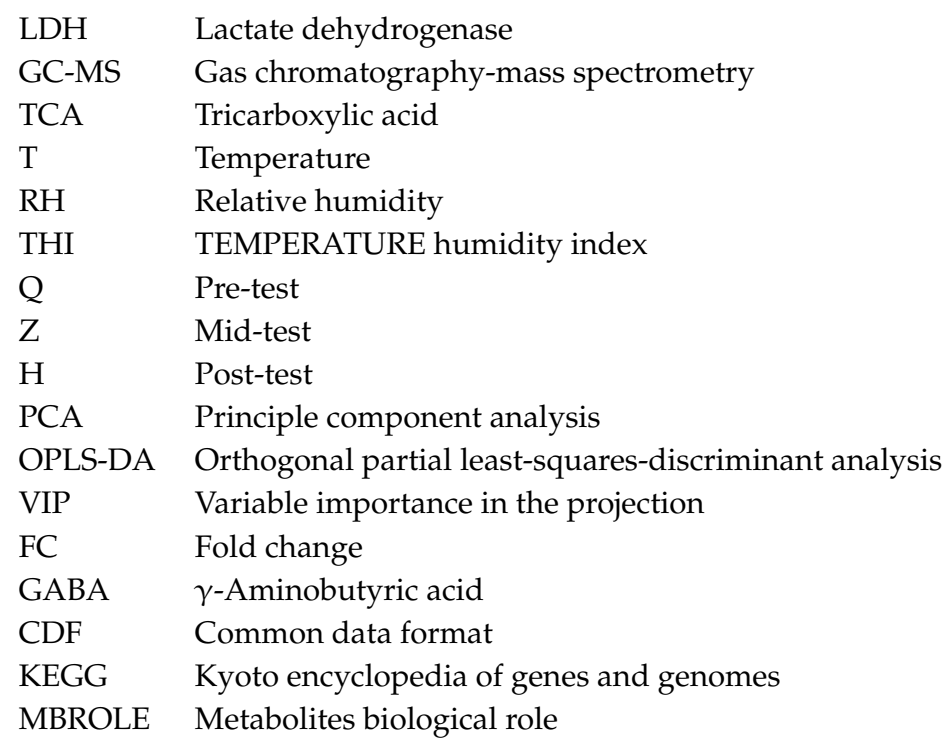

\section{References}

1. Ahmed, A.; Tiwar, R.P.; Mishra, G.K.; Jena, B.; Dar, M.A.; Bhat, A.A. Effect of environmental heat stress on reproduction performance of dairy cows-A review. Int. J. Livest. Res. 2015, 5, 10-18. [CrossRef]

2. Gernand, E.; König, S.; Kipp, C. Influence of on-farm measurements for heat stress indicators on dairy cow productivity, female fertility, and health. J. Dairy Sci. 2019, 102, 6660-6671. [CrossRef] [PubMed]

3. Dahl, G.E. Impact and mitigation of heat stress for mastitis control. Vet. Clin. N. Am. Small Anim. Pract. 2018, 34, 473-478. [CrossRef] [PubMed]

4. Yeh, H.S.; Weng, B.C.; Lien, T.F. Effects of Chinese traditional herbal medicine complex supplementation on the growth performance, immunity and serum traits of pigs. Anim. Sci. J. 2011, 82, 747-752. [CrossRef]

5. Xie, Z.; Zhang, J.; Ma, S.; Huang, X.; Huang, Y. Effect of Chinese herbal medicine treatment on plasma lipid profile and hepatic lipid metabolism in Hetian broiler. Poult. Sci. 2017, 96, 1918-1924. [CrossRef] [PubMed]

6. Zhang, D.F.; Sun, B.B.; Yue, Y.Y.; Zhou, Q.J.; Du, A.F. Anticoccidial activity of traditional Chinese herbal Dichroa febrifuga Lour. extract against Eimeria tenella infection in chickens. Parasitol. Res. 2012, 111, 2229-2233. [CrossRef]

7. Shan, C.H.; Guo, J.J.; Sun, X.S.; Li, N.; Yang, X.Y.; Gao, Y.H.; Qiu, D.R.; Li, X.M.; Wang, Y.Y.; Feng, M.; et al. Effects of fermented Chinese herbal medicines on milk performance and immune function in late-lactation cows under heat stress conditions. J. Anim. Sci. 2018, 96, 4444-4457. [CrossRef]

8. Yang, X.Y.; Liu, N.; Li, X.Y.; Yang, Y.H.; Wang, X.F.; Li, L.L.; Jiang, L.; Gao, Y.H.; Tang, H.B.; Tang, Y.; et al. A Review on the Effect of Traditional Chinese Medicine against anthracycline-induced cardiac toxicity. Front. Pharmacol. 2018, 9, 444. [CrossRef]

9. Fu, J.; Wang, Z.H.; Huang, L.F.; Zheng, S.H.; Wang, D.W.; Chen, S.L.; Zhang, H.T.; Yang, S.H. Review of the botanical characteristics, phytochemistry, and pharmacology of Astragalus membranaceus (Huangqi). Phytother. Res. 2014, 28, 1275-1283. [CrossRef]

10. Qiao, H.; Song, Y.Z.; Shi, H.T.; Bian, C.Z. Fermented Astragalus in diet altered the composition of fecal microbiota in broiler chickens. AMB Express 2018, 8, 151. [CrossRef]

11. Li, W.K.; Wang, F.G.; Wang, T.M.; Li, Y.Y.; Li, Y.F.; Lu, X.Y.; Wang, Y.H.; Zhang, H.; Liu, P. Protective effect of herbal medicine Huangqi decoction against chronic cholestatic liver injury by inhibiting bile acid-stimulated inflammation in DDC-induced mice. Phytomedicine 2019, 62, 152948. [CrossRef] [PubMed]

12. Mamedova, R.P.; Isaev, M. Triterpenoids from astragalus plants. Chem. Nat. Compd. 2004, 40, $303-357$. [CrossRef]

13. Gong, A.G.W.; Duan, R.; Wang, H.Y.; Kong, X.P.; Dong, T.T.X.; Tsim, K.W.K.; Chan, K. Evaluation of the Pharmaceutical Properties and Value of Astragali Radix. Medicines (Basel) 2018, 5, 46. [CrossRef] [PubMed]

14. Niu, Y.; Wang, H.Y.; Xie, Z.H.; Whent, M.; Gao, X.D.; Zhang, X.; Zou, S.; Yao, W.B.; Yu, L.L. Structural analysis and bioactivity of a polysaccharide from the roots of Astragalus membranaceus (Fisch) Bge. var. mongolicus (Bge.) Hsiao. Food Chem. 2011, 128, 620-626. [CrossRef] 
15. Wu, S. Effect of dietary Astragalus membranaceus polysaccharide on the growth performance and immunity of juvenile broilers. Poult. Sci. 2018, 97, 3489-3493. [CrossRef] [PubMed]

16. Zhai, Q.L.; Hu, X.D.; Xiao, J.; Yu, D.Q. Astragalus polysaccharide may increase sensitivity of cervical cancer HeLa cells to cisplatin by regulating cell autophagy. Zhongguo Zhong Yao Za Zhi 2018, 43, 805-812.

17. Meng, Q.; Du, X.Z.; Wang, H.L.; Gu, H.M.; Zhan, J.P.; Zhou, Z.P. Astragalus polysaccharides inhibits cell growth and pro-inflammatory response in IL-1beta-stimulated fibroblast-like synoviocytes by enhancement of autophagy via PI3K/AKT/mTOR inhibition. Apoptosis 2017, 22, 1138-1146. [CrossRef]

18. Chen, W.; Ju, J.; Yang, Y.H.; Wang, H.; Chen, W.J.; Zhao, X.L.; Ye, H.Y.; Zhang, Y. Astragalus polysaccharides protect cardiac stem and progenitor cells by the inhibition of oxidative stress-mediated apoptosis in diabetic hearts. Drug Des. Dev. Ther. 2018, 12, 943-954. [CrossRef]

19. Pang, H.H.; Jia, W.; Hu, Z.P. Emerging applications of metabolomics in clinical pharmacology. Clin. Pharmacol. Ther. 2019, 106, 544-556. [CrossRef]

20. Hailemariam, D.; Mandal, R.; Saleem, F.; Dunn, S.M.; Wishart, D.S.; Ametaj, B.N. Identification of predictive biomarkers of disease state in transition dairy cows. J. Dairy Sci. 2014, 97, 2680-2693. [CrossRef]

21. Wu, X.; Sun, H.Z.; Xue, M.Y.; Wang, D.M.; Duan, L.L.; Liu, J.X. Serum metabolome profiling revealed potential biomarkers for milk protein yield in dairy cows. J. Proteom. 2018, 184, 54-61. [CrossRef] [PubMed]

22. Tian, H.; Wang, W.Y.; Zheng, N.; Cheng, J.B.; Li, S.L.; Zhang, Y.D.; Wang, J.Q. Identification of diagnostic biomarkers and metabolic pathway shifts of heat-stressed lactating dairy cows. J. Proteom. 2015, 125, 17-28. [CrossRef] [PubMed]

23. Fan, C.Y.; Su, D.; Tian, H.; Hu, R.T.; Ran, L.; Yang, Y.; Su, Y.J.; Cheng, J.B. Milk production and composition and metabolic alterations in the mammary gland of heat-stressed lactating dairy cows. J. Integr. Agric. 2019, 18, 2844-2853. [CrossRef]

24. Zhong, K.; Yang, G.Y.; Wang, Y.L.; Zou, S.X.; Chen, W.H. Effect of Astragalus Polysaccharide on bovine experimental mastitis induced by endotoxin. Acta Ecol. Anim. Domastici 2007, 28, 5-8.

25. Zhang, X.H.; Wang, D.Y.; Hu, Y.L.; Sun, J.L. Immunologic enhancement of Astragalus polysaccharide (APS) on the humoral immunity of chicken. Chin. J. Vet. Sci. 2009, 29, 312-315.

26. Rutgers, L.J.E.; Van Miert, A.S.J.P.A.M.; Nouws, J.F.M.; Van Ginneken, C.A.M. Effect of the injection site on the bioavailability of amoxycillin trihydrate in dairy cows. J. Vet. Pharmacol. Ther. 1980, 3, 125-132. [CrossRef]

27. National Research Council (NRC). A Guide to Environmental Research on Animals; National Academy of Sciences: Washington, DC, USA, 1971.

28. Lu, T.; Ke, M.J.; Lavoie, M.; Jin, Y.J.; Fan, X.J.; Zhang, Z.Y.; Fu, Z.W.; Sun, L.W.; Gillings, M.; Peñuelas, J.; et al. Rhizosphere microorganisms can influence the timing of plant flowering. Microbiome 2018, 6, 231. [CrossRef]

29. Ingraham, R.H.; Gillette, D.D.; Wagner, W.D. Relationship of temperature and humidity to conception rate of holstein cows in subtropical climate. J. Dairy Sci. 1974, 57, 476-481. [CrossRef]

30. Li, S.G.; Zhang, Y.Q. Characterization and renal protective effect of a polysaccharide from Astragalus membranaceus. Carbohydr. Polym. 2009, 78, 343-348. [CrossRef]

31. Mao, X.; Wu, Y.; Wu, K.; Liu, M.; Zhang, J.F.; Zou, F.; Ouyang, J.P. Astragalus polysaccharide reduces hepatic endoplasmic reticulum stress and restores glucose homeostasis in a diabetic KKAy mouse model. Acta Pharmacol. Sin. 2010, 28, 1947-1956. [CrossRef]

32. Li, X.T.; Zhang, Y.K.; Kuang, H.X.; Jin, F.X.; Liu, D.W.; Gao, M.B.; Liu, Z.; Xin, X.J. Mitochondrial protection and anti-aging activity of astragalus polysaccharides and their potential mechanism. Int. J. Mol. Sci. 2012, 13, 1747-1761. [CrossRef] [PubMed]

33. Wheelock, J.B.; Rhoads, R.P.; Vanbaale, M.J.; Sanders, S.R.; Baumgard, L.H. Effects of heat stress on energetic metabolism in lactating Holstein cows. J. Dairy Sci. 2010, 93, 644-655. [CrossRef] [PubMed]

34. Baumgard, L.H.; Rhoads Jr, R.B. Effects of heat stress on postabsorptive metabolism and energetics. Annu. Rev. Anim. Biosci. 2013, 1, 311-337. [CrossRef] [PubMed]

35. Christison, G.I.; Johnson, H.D. Cortisol turnover in heat-stressed cows. J. Anim. Sci. 1972, 35, $1005-1010$. [CrossRef]

36. Johnson, H.D.; Vanjonack, W.J. Effects of environmental and other stressors on blood hormone patterns in lactating animals. J. Dairy Sci. 1976, 59, 1603-1617. [CrossRef] 
37. Weitzel, J.M.; Viergutz, T.; Albrecht, D.; Bruckmaier, R.; Schmicke, M.; Tuchscherer, A.; Koch, F.; Kuhla, B. Hepatic thyroid signaling of heat-stressed late pregnant and early lactating cows. J. Endocrinol. 2017, 234, 129-141. [CrossRef]

38. Magdub, A.; Johnson, H.D.; Belyea, R.L. Effect of environmental heat and dietary fiber on thyroid physiology of lactating cows. J. Dairy Sci. 1982, 65, 2323-2331. [CrossRef]

39. Liu, H.L.; He, J.H.; Xiao, B.N.; Zhang, B.Z. Effects of compound Chinese herbal medicine additives on production Performance, physiological and biochemical indexes of dairy cows under heat stress. Acta Ecol. Anim. Domastici 2011, 32, 82-87.

40. Itoh, F. Insulin and glucagon secretion in lactating cows during heat exposure. J. Anim. Sci. 1998, 76, 2182-2189. [CrossRef]

41. Song, X.; Luo, J.; Fu, D.; Zhao, X.; Bunlue, K.; Xu, Z.; Qu, M. Traditional Chinese medicine prescriptions enhance growth performance of heat stressed beef cattle by relieving heat stress responses and increasing apparent nutrient digestibility. Asian-Australas. J. Anim. Sci. 2014, 27, 1513-1520. [CrossRef]

42. Ibtisham, F.; Nawab, A.; Niu, Y.F.; Wang, Z.; Wu, J.; Xiao, M.; An, L.L. The effect of ginger powder and Chinese herbal medicine on production performance, serum metabolites and antioxidant status of laying hens under heat-stress condition. J. Therm. Biol. 2019, 81, 20-24. [CrossRef] [PubMed]

43. Safa, S.; Kargar, S.; Moghaddam, G.A.; Ciliberti, M.G.; Caroprese, M. Heat stress abatement during the postpartum period: Effects on whole lactation milk yield, indicators of metabolic status, inflammatory cytokines, and biomarkers of the oxidative stress. J. Anim. Sci. 2019, 97, 122-132. [CrossRef]

44. Zhang, H.W.; Lin, Z.X.; Xu, C.S.; Leung, C.; Chan, L.S. Astragalus (a traditional Chinese medicine) for treating chronic kidney disease. Cochrane Database Syst. Rev. 2014, CD008369. [CrossRef] [PubMed]

45. Zhang, K.; Pugliese, M.; Pugliese, A.; Passantino, A. Biological active ingredients of traditional Chinese herb Astragalus membranaceus on treatment of diabetes: A systematic review. Mini Rev. Med. Chem. 2015, 15, 315-329.

46. Zhang, R.; Qin, X.; Zhang, T.; Li, Q.; Zhang, J.X.; Zhao, J.X. Astragalus polysaccharide improves insulin sensitivity via AMPK activation in 3T3-L1 adipocytes. Molecules 2018, 23, 2711. [CrossRef] [PubMed]

47. Loranger, M.W.; Beaton, S.A.; Lines, k.L.; Jakeman, D.L. Thiophosphate and thiophosphonate analogues of glucose-1-phosphate: Synthesis and enzymatic activity with a thymidylyltransferase. Carbohydr. Res. 2013, 379, 43-50. [CrossRef]

48. Verzar, F.; Wenner, V. Glycogen production from glucose-1-phosphate by liver and muscle of normal and adrenalectomized animals. Biochem. J. 1948, 42, 42-48. [CrossRef]

49. Shi, C.X.; Zhao, M.X.; Shu, X.D.; Xiong, X.Q.; Wang, J.J.; Gao, X.Y.; Chen, Q.; Li, Y.H.; Kang, Y.M.; Zhu, G.Q. beta-aminoisobutyric acid attenuates hepatic endoplasmic reticulum stress and glucose/lipid metabolic disturbance in mice with type 2 diabetes. Sci. Rep. 2016, 6, 21924. [CrossRef]

50. Jung, T.W.; Park, H.S.; Choi, G.H.; Kim, D.; Lee, T. beta-aminoisobutyric acid attenuates LPS-induced inflammation and insulin resistance in adipocytes through AMPK-mediated pathway. J. Biomed. Sci. 2018, 25, 27. [CrossRef]

51. Moore, R.Y. Central catecholamine neuron systems: Anatomy and physiology of the norepinephrine and epinephrine systems. Annu. Rev. Neurosci. 1979, 2, 113-168. [CrossRef]

52. Starkie, R.L.; Hargreaves, M.; Rolland, J.; Febbraio, M.A. Heat stress, cytokines, and the immune response to exercise. Brain Behav. Immun. 2005, 19, 404-412. [CrossRef] [PubMed]

53. Gerich, J.; Cryer, P.; Rizza, R. Hormonal mechanisms in acute glucose counterregulation: The relative roles of glucagon, epinephrine, norepinephrine, growth hormone, and cortisol. Metabolism 1980, 29 (Suppl. S1), 1164-1175. [CrossRef]

54. Wahren, J.; Felig, P.; Cerasi, E.; Luft, R. Splanchnic and peripheral glucose and amino acid metabolism in diabetes mellitus. J. Clin. Investig. 1972, 51, 1870-1878. [CrossRef] [PubMed]

55. Suhre, K.; Meisinger, C.; Döring, A.; Altmaier, E.; Belcredi, P.; Gieger, C.; Chang, D.; Milburn, M.V.; Gall, W.E.; Weinberger, K.M.; et al. Metabolic footprint of diabetes: A multiplatform metabolomics study in an epidemiological setting. PLoS ONE 2010, 5, e13953. [CrossRef] [PubMed]

56. Abel, M.S.; McCandless, D.W. Elevated gamma-aminobutyric acid levels attenuate the metabolic response to bilateral ischemia. J. Neurochem. 1992, 58, 740-744. [CrossRef] 
57. Guo, K.; Guo, K.; Cao, H.B.; Zhu, Y.J.; Wang, T.C.; Hu, G.L.; Kornmatitsuk, B.; Luo, J. Improving effects of dietary rumen protected gamma-aminobutyric acid additive on apparent nutrient digestibility, growth performance and health status in heat-stressed beef cattle. Anim. Sci. J. 2018, 89, 1280-1286. [CrossRef]

58. Bai, L.; Pang, W.J.; Yang, Y.J.; Yang, G.S. Modulation of Sirt1 by resveratrol and nicotinamide alters proliferation and differentiation of pig preadipocytes. Mol. Cell. Biochem. 2008, 307, 129-140. [CrossRef]

59. Liu, X.; Fu, J.; Song, E.; Zang, K.; Wang, A. Effect of nicotinamide on proliferation, differentiation, and energy metabolism in bovine preadipocytes. Asian-Australas. J. Anim. Sci. 2009, 22, 1320-1327. [CrossRef]

60. Willams, A.C.; Cartwright, L.S.; Ramsden, D.B. Parkinson's disease: The first common neurological disease due to auto-intoxication? QJM 2005, 98, 215-226. [CrossRef]

61. Mustroph, A.; Hess, N.; Sasidharan, R. Hypoxic energy metabolism and PPi as an alternative energy currency. Plant Cell Monogr. 2014, 21, 165-184.

(C) 2020 by the authors. Licensee MDPI, Basel, Switzerland. This article is an open access article distributed under the terms and conditions of the Creative Commons Attribution (CC BY) license (http://creativecommons.org/licenses/by/4.0/). 